\title{
Traditional versus Modern? Perceptions and Preferences of Urban Park Users in Iran
}

\author{
Fariba Bahriny ${ }^{1, *}$ and Simon Bell ${ }^{1,2} \mathbb{D}$ \\ 1 Landscape Architecture, Estonian University of Life Sciences, Kreutzwaldi 56/3, 51006 Tartu, Estonia; \\ simon.bell@emu.ee or s.bell@ed.ac.uk \\ 2 Edinburgh School of Architecture and Landscape Architecture, University of Edinburgh, 74 Lauriston Pl, \\ Edinburgh EH3 9DF, UK \\ * Correspondence: faribabahrinyhu@gmail.com
}

check for

updates

Citation: Bahriny, F.; Bell, S. Traditional versus Modern? Perceptions and Preferences of Urban Park Users in Iran. Sustainability 2021, 13, 2036. https://doi.org/10.3390/ su13042036

Academic Editor: Jacques Teller Received: 28 December 2020

Accepted: 6 February 2021

Published: 13 February 2021

Publisher's Note: MDPI stays neutral with regard to jurisdictional claims in published maps and institutional affiliations.

Copyright: (C) 2021 by the authors. Licensee MDPI, Basel, Switzerland. This article is an open access article distributed under the terms and conditions of the Creative Commons Attribution (CC BY) license (https:// creativecommons.org/licenses/by/ $4.0 /)$.

\begin{abstract}
This study involved four parks in Iran-two modern ones located in Tehran and two historical, traditional examples, one in Kashan and one in Esfahan-in order to ask what are the key factors contributing to the satisfaction of visitors to the two types of park and also to compare user's perceptions and values of the different types. An extensive questionnaire survey was conducted in each park, with a target of 300 responses, using a random sampling technique. Respondents were asked to rate the importance of a number of factors, while thinking about the park they were visiting, using a 5-point Likert scale. Descriptive and inferential statistical analysis was undertaken. The results of the scores revealed differences between the two types of park. A factor analysis of the pooled results revealed that the key aspects contributing to a visit were named as 'having fun and enjoying oneself', in a place with 'no barriers to using the park' and 'leaving one's cares behind' followed by 'relaxing in the presence of natural beauty'. A further Nonmetric Multidimensional Scaling analysis was undertaken to determine the main factors affecting the differences in preference for each type of park in relation to the key demographic variables. This revealed that the modern parks were preferred over the traditional ones for three significant sets of factors-recreation, accessibility and culture - and that there was a tendency for the historical parks to been favoured by more educated people. The conclusions are that the modern parks support the main preferred activities to support the quality of life of the population-not through their design per se but because they offer many more recreational opportunities. There is potential to include traditional elements such as water features more into parks. Park planners can take the findings and use them to help improve the quality of the parks over time.
\end{abstract}

Keywords: Persian gardens; park design; factor analysis; nonmetric multidimensional scaling

\section{Introduction}

\subsection{The Role and Benefits of Urban Parks as Urban Open Spaces}

Globally, more than half the population now lives in cities [1]. The rate of urbanisation is higher in developing countries although urban sprawl occurs everywhere [2]. In the past century the rate of urbanisation has increased four-fold in Iran [3]. According to Soltani and Namdarian [4] political and social globalisation are the dominant forces, leading to a shift in the nature of financial and economic power as well as fundamentally altering political and management powers; through these social and political powers cities such as Tehran change.

As Clark and Jauhiainen [5] point out in their analysis of the development of key European cities, political and economic success leads to competition between cities and urban planning can be used to manage urban growth and improve liveability. Urban green and blue infrastructure, including parks, can play a major role in attracting businesses and people as well as attracting tourists and for city branding [6] and for offering spaces for improving the physical and mental health and well-being of residents [7]. Green (and 
blue) spaces in the urban environment also play a significant role in urban planning since they open a window into a society and they represent symbols of its cultural and social expression [8].

Urban parks in cities in many developing countries face enormous pressures due to urban sprawl and increasing populations [9]. Tehran, the capital of Iran, suffers from many social and environmental problems and it is not alone among Iranian cities in this respect. Without solving these problems, the next generation of Iranian urban citizens will suffer from worsening social and environmental conditions which will threaten their health [10]. As Moradiyan et al. [11] note, although the modern sedentary life style leads to health problems that can be offset by increased exercise there is also, in some cases, a lower willingness to use urban parks where city authorities appear to display a lack of concern about their safety, security and fitness for use by people of different ages and genders. Fortunately, in recent years, attention to green spaces has also increased because of the growth of consciousness about their role in decreasing stress [12] among other aspects. Other factors are also affecting the role of parks and green spaces in Iran, such as increasing numbers of people living in densely built apartment buildings, over-population leading to overcrowding in poor districts, smaller house size meaning less living space per inhabitant and increases in the age of marriage, all of which lead to younger people, especially, spending more time in parks as places where they be alone or be with friends. As a result, more attention is being paid to green spaces in cities in Iran [13].

Urban parks, when well-planned, designed and managed, are among the spaces which can provide increasing benefits for urban life quality and perform multiple functions ranging from increasing economic benefits through social integration and community development potential, to therapeutic benefits [14-17]. As well as environmental services, parks also provide many recreational, aesthetic and psychological advantages $[18,19]$ including taking part in social activities such as playing games, music, arts and physical activity as well as being places where people congregate to socialise with families and friends [20]. Many studies have concluded that recreation and leisure activities promoting a healthier lifestyle are increasingly popular in urban parks. This increase was noted for Iran over 10 years ago [21] and Ghandehari [22] in another Iranian study, concluded that due to decreasing levels of exercise among the population, all citizens should be encouraged to be active in their life. Green exercising in a pleasant environment has been shown to have beneficial effects on people [23].

Regular recreation in urban parks has been demonstrated to have positive effects on mood and feelings of revitalisation [24,25] while other studies showed contact with nature reduced negative affective states such as stress, depression, anxiety, tension, confusion, anger and loneliness [26,27]. Furthermore, many positive influences on a person are claimed, such as pleasure and enjoyment, enhanced feeling of the body, experiences of flow, comfort and intense emotions, independence, competence and nature relatedness [28,29]. One of the motivations for people to use urban parks, especially in dense and crowded cities, is to find a relatively calm and peaceful environment, especially at holiday times and weekends [30,31].

Research into preferences for factors affecting park use has been conducted in numerous studies using different methods and has found that aspects such as users' perceptions of security in urban parks $[9,32,33]$ the provision of park facilities $[34,35]$ as well as accessibility [36] are some of the main predictors of satisfaction. Therefore, improved knowledge about different user groups, their cultural situation and needs in interaction with the environment can help improve the function and as a result, parks' environmental balance, stability and sustainability and to make lively spaces with sufficient security $[37,38]$.

\subsection{Responding to the Needs and Functions of Urban Parks}

In a study in Iran which looked at the repurposing of traditional gardens for modernday needs, Sharefi [37] concluded that designing urban spaces would be most successful when responding to a range of human needs. Concentrating on one level or set of needs 
reduces the adaptability and flexibility of a park in relation to different user groups in space and over time. In this situation, the probability of the presence of antisocial or delinquent groups will increase and as a result, the likelihood of other social groups being present will be lower [9].

Thus, the more the park matches the main subjectively expressed preferences of the dominant actual and potential user groups and the better the understanding of this by planners, the more we can expect people to welcome such parks. If park users have different expectations from what planners perceive, it may lead to some tensions between different groups, as some will come to the park to rest, for example, but they may be disturbed by other people's exercise or children playing; similarly, adults performing exercise may cause problems for children who are playing. Therefore, being aware of people's subjective preferences and perceptions about urban parks is necessary in order to be able to establish a pattern for their design and development. As Suhardi [39] points out, in a study in a large park in Malaysia, if designers understand the people's needs and behaviour when they interact with their environment, then they can create more successful urban parks. Pasban Hazrat [40], an Iranian park designer, also considers that urban parks should be designed according to the needs of people. In Iran there is a particular tradition of garden and park design whose legacy should be respected even when considering what are the contemporary needs of the users as well as learning from the international trends in park design and in using the scientific evidence, to inform how best to design a park.

\subsection{The Persian (Iranian) Garden}

Using urban parks and green space has long been a major part of Iranian culture with a grand tradition of garden creation dating back centuries to different Persian styles and heritage [41]. The classic Persian garden (we refer here to the tradition as Persian rather than Iranian as this is how it is known internationally) was formed at the same pace as the evolution of Persian civilization and culture. Persian gardens, like Persian architecture, evolved so as to match the ecosystem and the climate-which is in most places hot and dry-and to offer specific conditions for the users of the gardens such as shading and cooling using natural air flow, vegetation and, above all, water, both still and moving. The plan of the garden is usually oriented on a north-south axis and, where possible, making use of natural slopes to maximise the view. The classical Persian style is known as the 'four square' garden, where the plan is divided into four squares by a cross-shaped water feature, traditionally with a pavilion at the centre. Along the main axes of the garden tall trees form enclosing and shading elements and help to promote a flow of cool air towards the central pavilion which also has the best views within the garden (and also out from it) [42].

The Persian garden is a reflection of Persian/Iranian philosophy; it is a place to be used for rest, relaxation and as a setting for cultural activities and its perfection has resulted from the combination of architectural elements with decorative planting of trees and flowers and the effect of water. It has been formed from a combination of Islamic art principles and culture in combination with the climate [43]. Contemporary Iranian landscape designers advocate a return to the much more sustainable approaches which, as noted earlier, evolved to take account of both culture and climate [44]. Such a return would potentially enable significant cost savings and also contribute to a new and updated interpretation of traditional forms to reflect the development of society. Therefore, it is argued that it is necessary to pay more attention to Persian garden principles, geometry, the most suitable kinds of flowers and trees and still and flowing water besides shady tall trees and full ponds [44].

\section{Understanding the Persian Garden Space through Concentrating the Senses}

One of the key characteristics of the Persian garden is the way in which all five senses are harnessed in order to perceive and understand the environment. The geometrical structure and all the various components and elements of the garden-built forms, water features, flowing plants and trees-are composed so as to concentrate the sensory expe- 
rience. Visual forms, scents of flowers, sounds of water, feelings of touching water, or tasting of fruits are brought together in a very intense way. The formal layout of paths is determined by the geometrical structure and incorporates direct and sometimes crossing (perpendicular to each other) movement axes. Incorporating a variety of spaces and senses is more interesting. When moving in the along paths, a person can see running water which is moving in the same or in the opposite direction. Changing light and the intensity of floral scents after rain or in cooler weather also affect all the five senses. Sight is the first main sense perceiving and understanding the garden space and its geometry. The water constantly varies from being visible to being hidden and the water surface of the pool increases the amount and quality of light and brightness through reflection [44].

The sense of hearing is exploited through the introduction of a variety of water sounds and also by birdsong. Taste and smell are combined in the flavour of fruit while scents of jasmine and roses perfume the air. The sense of touch has an especially significant role in the Persian garden. Feeling moisture on the skin and dangling fingers or feet in the cool water has an intense effect and helps to create the feeling of being in a secluded and calm place [45]. Of course, throughout most of history such gardens and their experiences were only available to the elite. In recent times, however, everyone can enjoy the special atmosphere when they visit them and many are on the world heritage list of UNESCO, although it is usually necessary to pay an entrance fee.

\subsection{Historical Transformation of Urban Parks in Iran}

Urban parks have a strategic importance for liveability and for the quality of life in Iranian urban society [46]. As noted above, they were only private gardens for the elites during most of history until the modernisation of Iran in the 20th century (Reeves, 2000). During industrialisation, the needs for public spaces were recognised in Europe and America and then the concepts were imported to Iran along with other aspects of modernisation [39]. Social and cultural transitions created different approaches; the concept of urban parks re-emerged and started to become part and parcel of the contemporary urban fabric.

As Hamzenejad and Gorji [13] noted, in every period, political, social, economic and cultural situations have a direct effect on park patterns and styles. In the period of Shah Pahlavi II the pace of modernisation in Iran increased and many influences from Europe and America could be seen in the development of new parks which were mostly organic/naturalistic in their layout, casting aside the forms and spirit of the classical Persian garden in favour of more general recreation by the masses and for the purpose of promoting different forms of social relationship as secularisation of society took place before the Islamic Revolution. In park building of the early revolution period the focus was on functional aspects of parks and in some cases mainly on cultural aspects (by incorporating theatres or art centres) and then on the visual attractiveness of parks through colourful planting. Later, some huge parks were established in the south of Tehran in an attempt to establish some social justice and to tackle inequality (not always very successfully). As far as can be ascertained, the shift of park planning and design away from traditional Persian forms to those borrowed from international models had no basis in research or in assessing the preferences or perceptions the people. Microclimate played no role, nor the efficiency of management and maintenance. As Bahrini and Bell showed in their previous study [9], the parks tend to contain a wide mix of facilities for recreation and entertainment and can often be found in poor condition. If, as Naima and others suggest [44], and in the interests of more sustainable park design, there should be a rediscovery of traditional Persian park design, then it is necessary to find out to what extent such a move would also satisfy the users.

\section{Research Objective and Questions}

The main objective of this paper is to examine the extent to which historical gardens and more modern urban parks in Iran match contemporary society's needs and people's 
expectations. We wish to see if there are particular elements found in traditional parks which are insufficiently included in contemporary ones. In order to determine this, we ask the following research question:

- What are the Iranian people's current needs and priorities for a good park and to what extent do they vary depending on whether a park is contemporary or traditional?

\section{Materials and Methods}

The study is based around a comparison of four Iranian gardens/parks: two relatively modern parks and two classical Persian gardens. A small-scale simple Delphi study [47] was used to elicit the main features which experts considered should be included in parks and gardens and then a questionnaire survey, the contents of which were based on the outcome of the Delphi study, was used to obtain information from users about their views of park features in relation to the four parks surveyed.

\subsection{Study Context}

Two modern parks and two traditional Persian gardens were selected as the case studies in the research: Mellat and Jamshidieh parks located in Tehran are two representative and popular modern parks while Bagh-e-Phin at Kashan and Chehelsotoon in Isfahan are two famous traditional gardens open to the public (although a fee must be paid). Tehran is the capital of Iran but developed relatively recently in Persian/Iranian history and does not have traditional gardens which is why we went to Kashan and Isfahan, historically important cities, for the two traditional garden examples.

Mellat park is a large municipal urban park in northern Tehran. It was built in 1967. It was designed to be informal in the English style with winding paths and a large organically shaped lake. It has an area of about 34 hectares. It is one of the largest green spaces in Tehran.

Jamshidieh park is a large park located in the north and at the edge of Tehran. It was built in two sections, the first in 1978 and the second in 1995. It is notable for its hilly, steep terrain offering extensive views over the city (when the air pollution permits). This modern park incorporates some traditional Iranian elements but not specifically in its form. It features stone statues and a waterfall in a mountainous location. It is 69 ha in area.

Kashan and the Bagh-e-Phin garden are located in a desert region where the microclimate was a major influence in architecture and garden design, the garden being, in its way, a kind of oasis in the desert. The garden is walled and contains a series of pools and channels, the flowing water of which is fed by the Solaymanieh Fountain. It is noted for many cypress trees which give it a strong character. The garden extends to 2.3 hectares, so much smaller than either of the two modern parks.

Isfahan is an ancient city and World Heritage site with many monuments from the Safavid dynastic times. Isfahan flourished from 1050 to 1722, particularly in the 16th and 17th centuries under the Safavid dynasty. The Chehelsotoon was built by Shah Abbas II for entertainment and receptions. The pavilion with twenty columns is located in the middle of a garden with a reflecting pool in front. The reflection of the twenty columns on the pool produces forty columns, which is what the name Chehelsotoon means. The garden is filled with mature trees and a network of paths laid out in the classical geometrical pattern. It covers some 6.2 hectares in area. Figure 1a-d shows recent satellite images of all four parks while Figure 2a-d shows some representative photos of each park. As Mellat and Jamshidiyeh are rather large the images only show a small part while for Baghe-Phin and Chehelsotoon the photos show the main axis and pavilion, which captures their character well. 


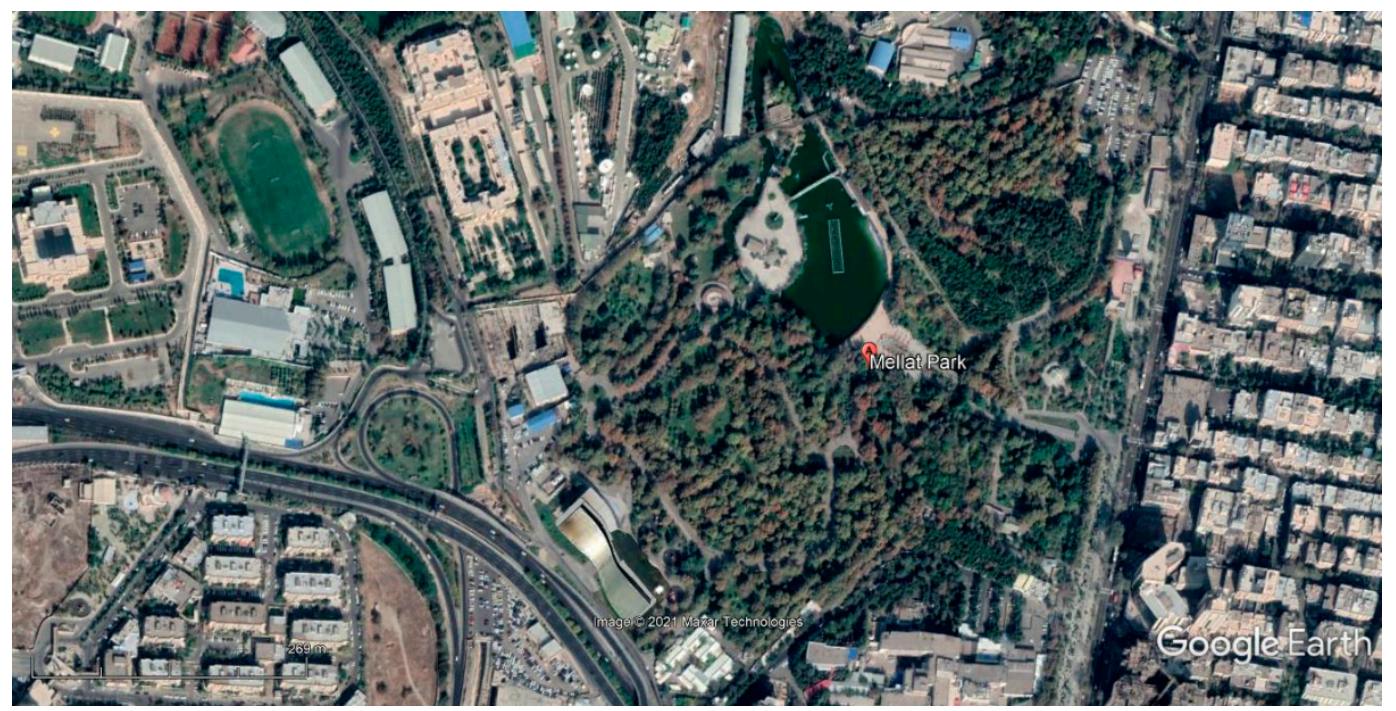

(a)

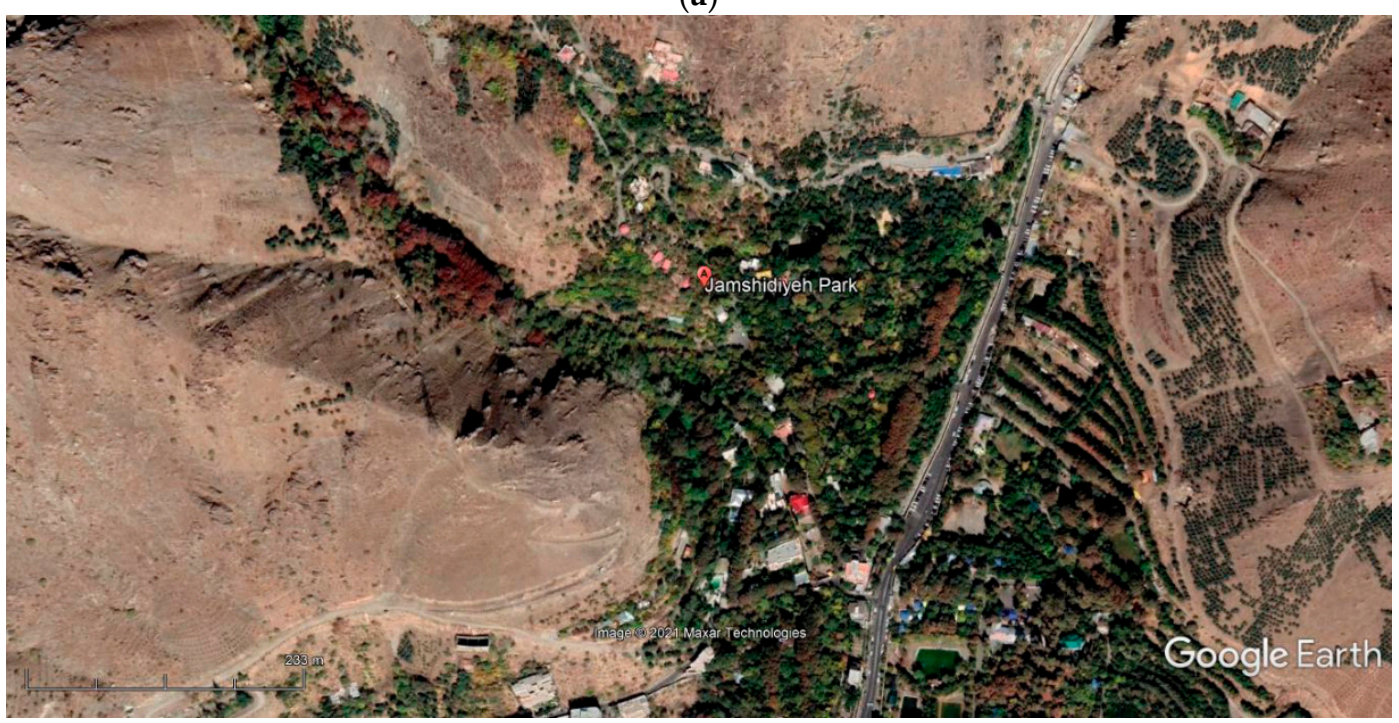

(b)

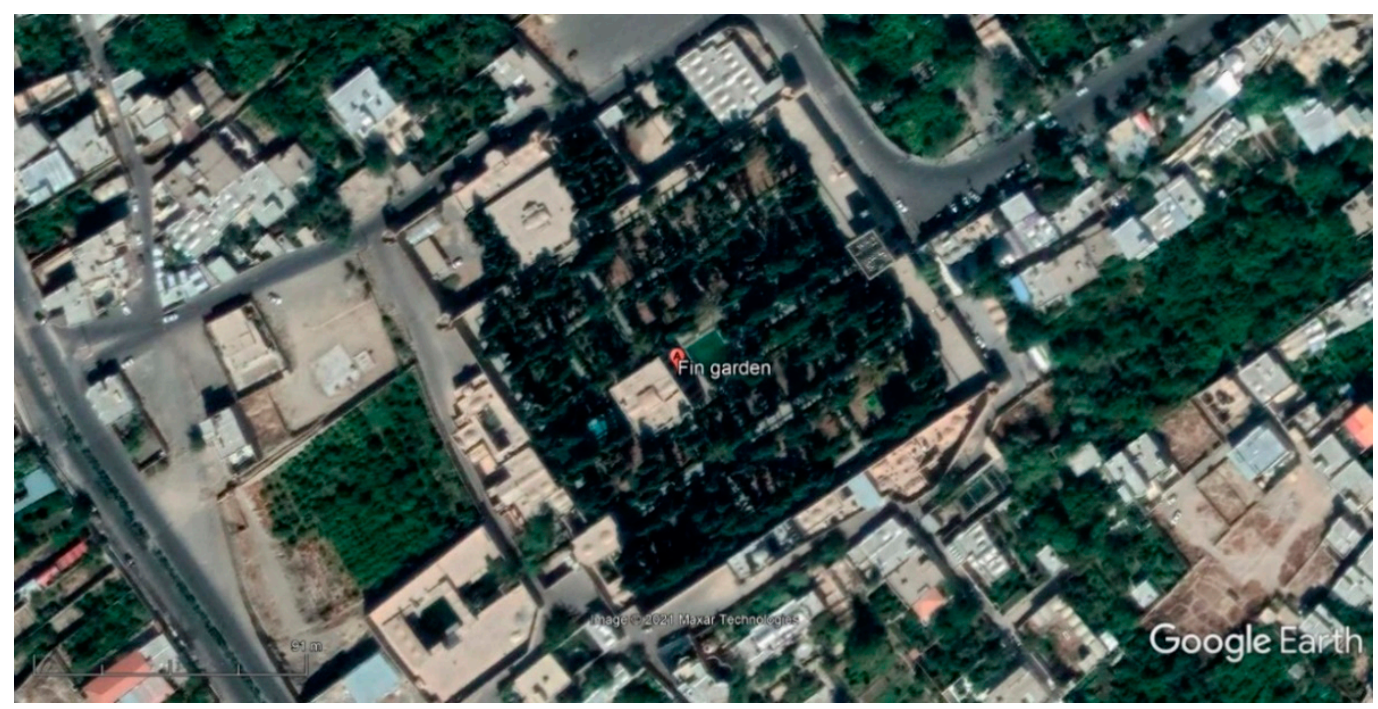

(c)

Figure 1. Cont. 


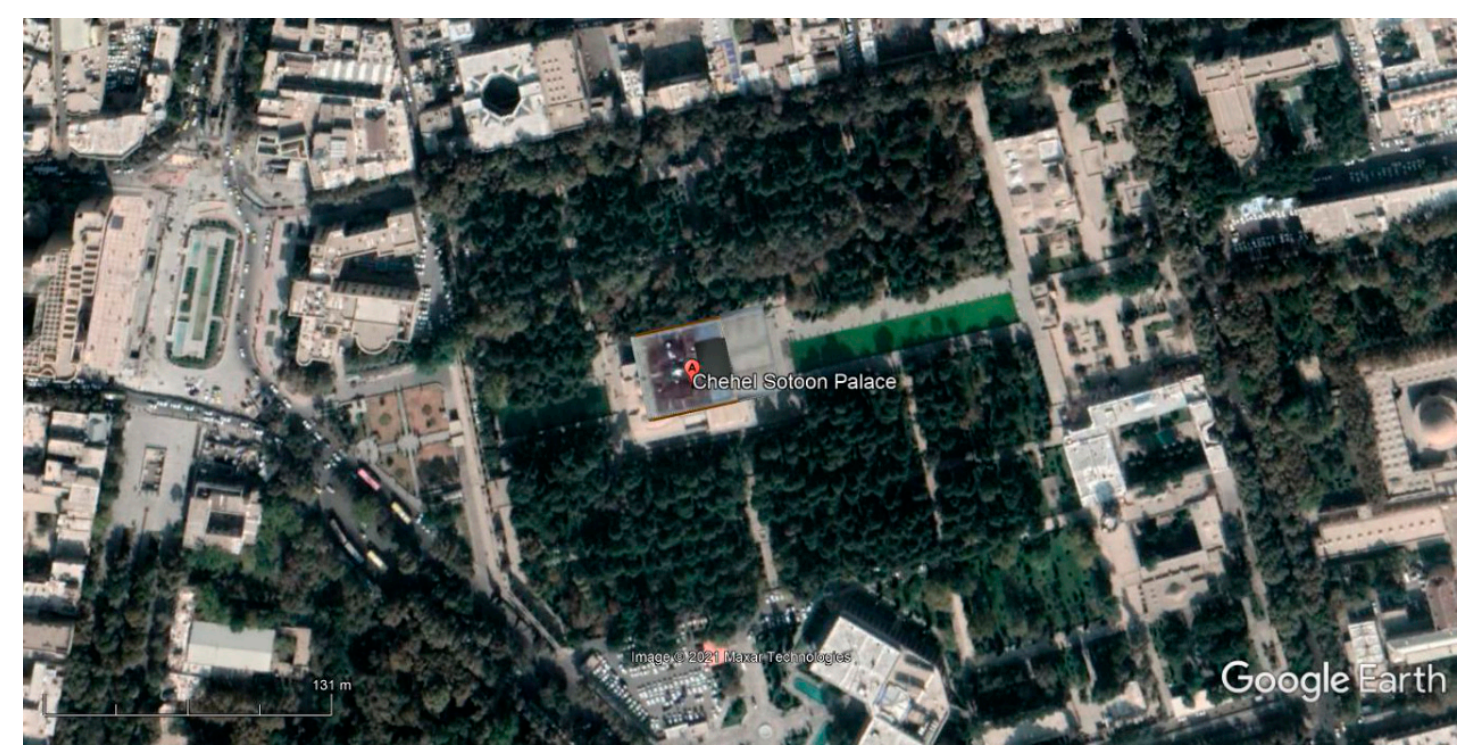

(d)

Figure 1. (a-d): Aerial views of the four parks used in the study: (a) Mellat Park, (b) Jamshidieh Park, (c) Bagh-e-Phin Garden and (d) Chehelsotoon Garden (Source: (c) GoogleEarth, 2021; (c) Maxar Technologies, 2021).
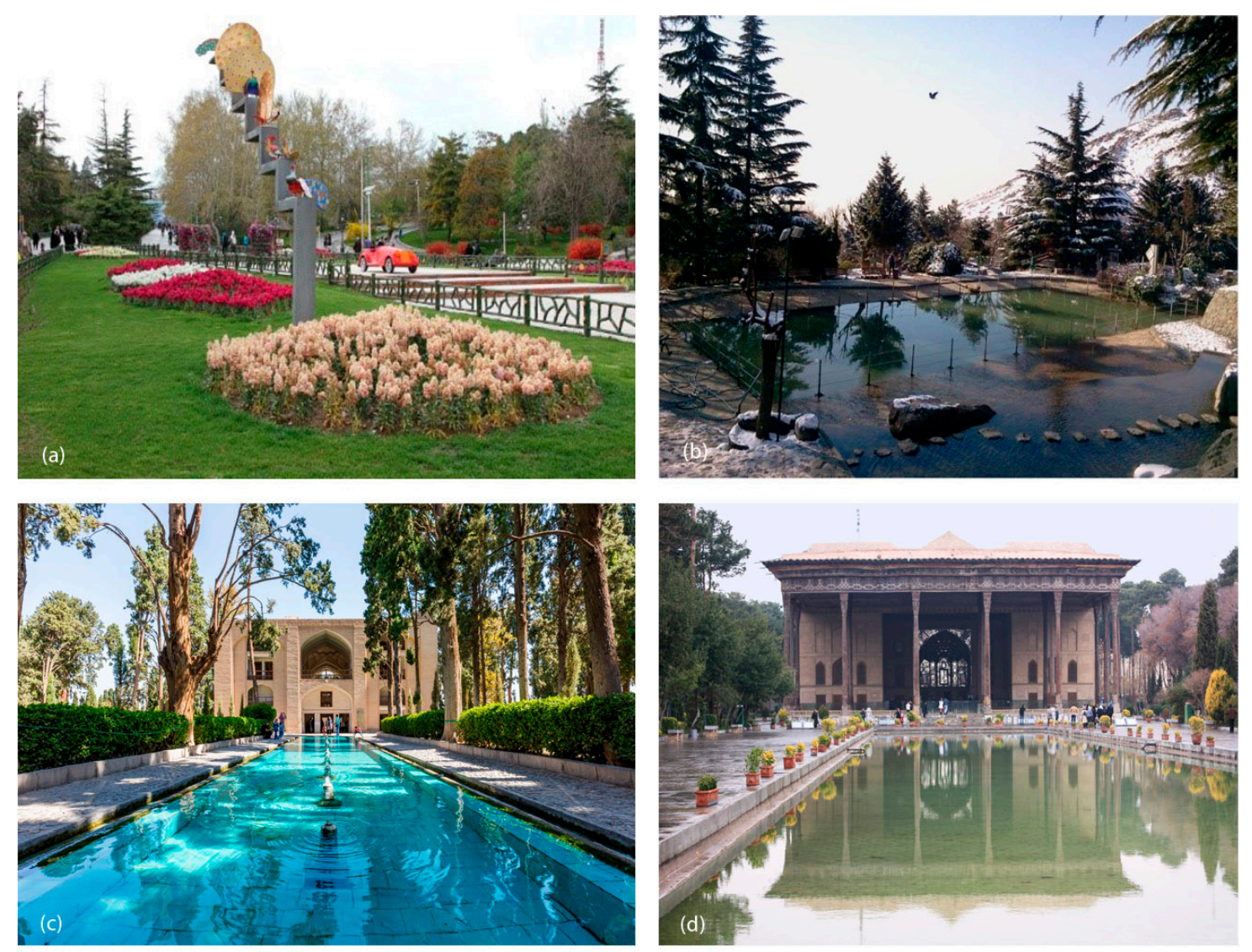

Figure 2. (a-d): (a) Mellat Park, with formal avenues and many curved paths and rich planting including colourful flowers (Source: Fariba Bahriny); (b) Jamshidieh Park, a large park in hilly, rocky topography, waterbodies and views out over the city (Source: Fahriba Bahriny); (c) Bagh-Phin garden in Kashan enclosed by a high wall with dense trees in a desert city, forming a kind of artificial oasis (Source: Diego Delso, Creative Commons License CC BY-SA 4.0); (d) Chehelsotoon garden in Esfahan (Source: Creative Commons Attribution-Share Alike 3.0 Unported). 


\subsection{Study Design and Data Collection Procedure}

\subsubsection{Developing the Questionnaire}

The questionnaire contents were developed first, by identifying all possible factors, from the literature, which could affect people's use, preference and perception of urban parks. This was tested by carrying out a small-scale and simple Delphi survey with Iranian experts on parks, urban planning and landscape design. We felt that this would be an effective way of focusing on those factors which have most relevance under Iranian conditions $[48,49]$ as a method for obtaining a convergence of opinions from multiple experts. A pilot test was carried out with five experts to ensure that they understand the terminology and the system [50]. Then a panel of 15 experts was formed representing experienced urban planners and landscape architects from companies, universities and the municipality. The panel was asked to prioritise each of the identified factors in two rounds - their first initial round where they ranked them independently, followed by a second round where they were asked to review their first scores in the light of the averages from all panel members in the second round. From this the final ranked list was obtained of factors which were then used to structure the survey questionnaire. All the 42 factors finally selected were arranged according to the following categories: (1) recreational, (2) security, (3) design elements, (4) spirituality, (5) accessibility, (6) cultural activities.

The experts were asked if they agreed that the items were relevant and they could suggest any they considered irrelevant to be removed from the final list following the ranking of the results of the second round all 42 items were considered to be relevant and none were therefore excluded. The averaged ranked items were then presented to the panel and checked again in round two to see if they agreed with the list. There was no significant change in any rankings so the entire set of factors was used.

\subsubsection{Structure and Administration of the Questionnaire}

The questionnaire survey instrument was devised to explore the opinions of visitors to the four parks described in the previous section, according to their preferences for different aspects. The questions were designed to elicit a level of importance given by the respondent to each factor using a 5 point Likert scale (ranging from 1 'Very Low Importance' to 5 'Very High Importance') - these were the dependent variables. Information on the respondents' age, gender, marital status, employment and educational level was also collected-these were the independent variables. The questions were directly based on the themes used in the Delphi study but their order was randomised to help reduce bias in completing the questionnaire. The final survey instrument (in English translation from the Farsi original) can be found in Appendix A. On being presented with the questionnaire, respondents were asked to complete it based on their preferences for a list of typical park features, reflecting as they did so on the park they were visiting at the time, so that we could determine if any differences arising could potentially be associated with the different types of park. We also expected that there would be some differences in preference due to the demographic profiles of the people who had chosen to visit those particular parks.

After pilot testing of the questionnaire, to ensure that the questions were understood by typical respondents, it was administered face to face by the researcher and her assistants. The self-administered questionnaire form was randomly distributed among park visitors on a Tuesday (mid-week day) and a Friday (holiday) between 9 am and 12 noon, then, after the afternoon break when parks tend to be empty, from $4 \mathrm{pm}$ until closing time (6 pm) for the two traditional parks (which closed early as they are not generally open but require a ticket) and up to midnight in the two modern parks (reflecting the usual temporal pattern of use). The data were collected in early July, August and September, 2016. The target was to collect 300 completed surveys and in total, 1181 fully completed usable questionnaires were obtained (almost 300 from each park).

Respondents filled in the questionnaire while they were present in the park and the completed ones were collected afterwards by the research team. A random sample was achieved by asking every tenth person encountered to participate and if someone refused 
then the next person was asked. This approach meant that a high proportion of the visitors present could be sampled and that the proportions of visitors would be representative of the users as a whole. Owing to the cultural sensitivities the study required an instrument that could guarantee confidentiality and both male and female researchers/research assistants were used, the females being freer to approach women and to ask them to fill out a questionnaire than a male researcher. We also followed the advice of Ary et al. [51] who suggest that questionnaires administered this way assure confidentiality of the respondents and may elicit more truthful responses. Very few people refused to participate and many showed a great deal of interest when the subject of the questionnaire was explained to them.

\subsubsection{Data Processing and Checking}

The data were manually transferred into an Excel database, cleaned and tested for validity and then analysed using the Statistical Package for Social Sciences (SPSS) version 19.0 for Windows. A mix of descriptive statistical analyses were run. Factor analysis was used to analyse the degree of variability and the significance of the findings in the data. A Cronbach's Alpha test was used to check the internal consistency of the data, that is, how closely related a set of items are as a group-it is considered to be a measure of scale reliability. A value above 0.6 shows an acceptable level of consistency among the data, and as Table 1 shows, all categories in the questionnaire were higher than this which showed a good internal consistency.

Table 1. Cronbach's Alpha test of the questionnaire items. Numbers greater than 0.6 denote a high level of internal consistency.

\begin{tabular}{cccc}
\hline Categories & Number of Items & Questionnaire Items (Question Numbers) & Cronbach's Alpha \\
\hline Design elements & 10 & $1,14,15,17,20,23,24,25,28,29,30,33$ & 0.692 \\
Accessibility & 6 & $18,21,27,37,38,39$ & 0.616 \\
Cultural activities & 4 & $10,11,13,22$ & 0.687 \\
Security & 3 & $19,26,34$ & 0.694 \\
Spirituality & 6 & $31,40,41,42$ & 0.651 \\
Recreation & 12 & $2,3,4,5,6,7,8,9,12,16,32,35,36$ & 0.723 \\
\hline
\end{tabular}

\subsubsection{Demographic Characteristics of the Respondents}

Demographic characteristics comprised gender, marital status and degree of education. The characteristics of the sample are shown in Table 2.

Table 2 shows that there were slightly more men in the complete sample of all the parks and also that single persons of both genders were slightly in the majority. Employed people make up the majority, with students also a major group while women dominate the homemaker status. A small majority of respondents had university degrees. More men than women respondents had only a basic education. Visitors to the parks are generally young. The average age of the sample is 29 years without any major age difference between women and men. This can be accounted for by the large number of students present in the sample.

\subsubsection{Data Analysis}

For the analysis we first examined the dataset and found that there were missing answers for some questions. However, we kept all the responses when we were analysing the separate questionnaire items. We conducted Cronbach's Alpha tests on all the sets of different factors in order to see if there were significant differences among the sets for each of the four parks. Then we summarised the findings using the mean scores of the 5-point Likert scales and tabulated these with the standard deviations for reporting purposes. 
Table 2. Demographic characteristics of the respondents: number and \% (in brackets).

\begin{tabular}{|c|c|c|c|c|c|}
\hline Demographic Factor & & Mellat & Jamshidieh & Bagh-e-Phin & Chehelsotoon \\
\hline \multirow{2}{*}{ Gender } & Male & $125(43.7)$ & $165(57.1)$ & $163(54.3)$ & $171(56.1)$ \\
\hline & Female & $161(56.3)$ & $124(42.9)$ & $137(45.7)$ & $134(43.9)$ \\
\hline \multirow[b]{2}{*}{ Marital status } & Single & $125(43.7)$ & $167(57.8)$ & $130(43.3)$ & $216(70.6)$ \\
\hline & Married & $161(56.3)$ & $122(42.2)$ & $170(56.7)$ & $90(29.4)$ \\
\hline \multirow{6}{*}{ Occupation } & Employed: governmental & $53(19.9)$ & $71(26)$ & $90(31.5)$ & $62(21.2)$ \\
\hline & Employed: non-governmental & $29(10.9)$ & $55(20.1)$ & $71(24.8)$ & $97(33.2)$ \\
\hline & Student & $80(30.1)$ & $85(31.1)$ & $51(17.8)$ & $89(30.5)$ \\
\hline & Homemaker & $35(13.2)$ & $18(6.6)$ & $32(11.2)$ & $7(2.4)$ \\
\hline & Retired & $37(13.9)$ & $18(6.6)$ & $17(5.9)$ & $4(1.4)$ \\
\hline & Unemployed & $32(12)$ & $26(9.5)$ & $25(8.7)$ & $33(11.3)$ \\
\hline \multirow{5}{*}{ Educational status } & Basic education & $5(1.8)$ & $0(0)$ & $4(1.3)$ & $2(0.7)$ \\
\hline & under diploma & $54(19.3)$ & $47(16.3)$ & $95(31.8)$ & $29(9.7)$ \\
\hline & High school diploma & $92(32.9)$ & $55(19.1)$ & $115(38.5)$ & $63(21)$ \\
\hline & Bachelor/student & $125(44.6)$ & $175(60.8)$ & $77(25.8)$ & $203(67.7)$ \\
\hline & Higher degree & $4(0.014)$ & $11(0.038)$ & $8(0.027)$ & $3(0.01)$ \\
\hline \multirow{5}{*}{ Age } & $<20$ & $95(33.9)$ & $74(25.6)$ & $65(22.3)$ & $66(21.6)$ \\
\hline & $20-30$ & $80(28.6)$ & $113(39.1)$ & $81(27.8)$ & $214(69.9)$ \\
\hline & $30-40$ & $33(11.8)$ & $60(20.8)$ & $71(24.4)$ & $19(6.2)$ \\
\hline & $40-50$ & $34(12.1)$ & $14(4.8)$ & $20(6.9)$ & $3(1)$ \\
\hline & $>50$ & $38(13.6)$ & $28(9.7)$ & $54(18.6)$ & $4(1.3)$ \\
\hline
\end{tabular}

The second approach to analysis was to run a factor analysis of all the questionnaire items. This was carried out using principal component analysis with a Varimax rotation and Kaiser Normalization. It revealed 11 factors which were named according to the combination of elements within each.

As we also wanted to test if there were any identifiable preferences between the two types of park - the modern and the traditional, and with so many factors evaluated within the questionnaire data as a whole, it was necessary, first, to establish which, if any, of the classes of factors predicted preferences. To do this we used the 'envfit' function provided by the 'Vegan' package in $\mathrm{R}$ (Project R, version 4.0.3) to process this analysis (Table 3), which determined that three categories of factors were significant, those for accessibility at the $0.001 p$-value level and for cultural activity and recreation at the $0.0 p$-value level. Because of the missing answers to some of the questions the number of valid questionnaires used in this analysis was reduced to 920.

Table 3. The results of fitting aggregated 920 questionnaires collected from the four parks and 42 variables grouped into the six categories revealing that ('accessibility', 'cultural activity' and 'recreation') on Nonmetric Multidimensional Scaling (NMDS) ordination of samples using the 'envfit' function provided by Vegan package in R. Significance was analysed by a Monte-Carlo randomisation test with 999 permutations. $\operatorname{Pr}(>\mathrm{r})$ - permutation $p$-value.

\begin{tabular}{ccccc}
\hline & NMDS1 & NMDS2 & r2 & Pr(>r) \\
\hline Design features & -0.71759 & 0.69647 & 0.0032 & 0.218 \\
Accessibility & 0.86344 & -0.50445 & 0.0146 & $0.003^{* *}$ \\
Cultural activity & 0.16903 & -0.98561 & 0.3103 & $0.001^{* * *}$ \\
Security & -0.58993 & -0.80745 & 0.0005 & 0.779 \\
Spirituality & -0.24110 & -0.97050 & 0.0006 & 0.746 \\
Recreation & 0.24337 & -0.96993 & 0.2891 & $0.001^{* * *}$ \\
\hline
\end{tabular}

Significance codes: $0^{* * *} 0.001^{* *}$. Permutation: free; number of permutations: 999.

To detect the similarity or differences among the respondents for the selected parks, we used Nonmetric Multidimensional Scaling (NMDS) [52,53]. This focuses on collapsing 
information from multiple dimensions (e.g., from multiple parks, many questionnaire variables, etc.,) into a smaller, more manageable number. From the questionnaire matrix, a Bray-Curtis dissimilarity matrix was computed and subjected to NMDS (metaMDS function with two-axis; 'Vegan' library in R). We fitted the aggregated demographic and environmental categories of 'accessibility', 'cultural activity' and 'recreation' which were significant (based on $\mathrm{p}$ value) on NMDS ordination of our data which related to each of the four parks.

\section{Results}

\subsection{Comparison of Preferences for Different Features across All Four Parks}

In this section different categories of factors are compared to see if there are any significant differences in preference rankings across each of the gardens/parks and whether modern or traditional ones appear to be favoured in general. These results relate to the first part of the research question. In interpreting the Likert scale we took a mean score of over 3.5 to represent the higher ranges and below 2.5 to represent the lower ranges with a range of between 2.5 and 3.5 to mean a moderate preference.

\section{Key Design Elements}

The results of chi square test for the key design elements (Table 4) revealed that there was a significant difference across the four parks: overall, in descending order of degree of difference are: the presence of flowing water; signs and information; shade; places to sit and relax; light coloured street furniture; ornamental fountains; lighting; beautiful landscape design and trees and flowers. The means of the Likert scale preference scores (1-5 scale for each) are presented together with the standard deviations (Table 5).

Table 4. Results of the Pearson chi-square test on the factors comprising the key design elements.

\begin{tabular}{ccccc}
\hline Key Design Elements & Pearson Chi-Square & df & $p$ Value & N \\
\hline Ornamental fountains & 83.711 & 12 & $<0.01$ & 1148 \\
Trees and flowers & 67.998 & 12 & $<0.01$ & 1148 \\
Beautiful landscape design & 69.953 & 12 & $<0.01$ & 1142 \\
Signs and information & 123.684 & 12 & $<0.01$ & 1151 \\
Light coloured street furniture & 85.958 & 12 & $<0.01$ & 1136 \\
Lighting & 73.884 & 12 & $<0.01$ & 1151 \\
Shade & 108.353 & 12 & $<0.01$ & 1139 \\
Flowing water & 135.348 & 12 & $<0.01$ & 1106 \\
Places to sit and relax & 90.711 & 12 & $<0.01$ & 1151 \\
\hline
\end{tabular}

Table 5. Means and standard deviations for each of the design factors compared across each of the four sample parks.

\begin{tabular}{ccccccccc}
\hline $\begin{array}{c}\text { Importance of Different } \\
\text { Design Elements }\end{array}$ & \multicolumn{2}{c}{ Mellat } & \multicolumn{2}{c}{ Jamshidieh } & \multicolumn{2}{c}{ Bagh-e-Phin } & Chehelsotoon \\
& Mean & SD & Mean & SD & Mean & SD & Mean & SD \\
\hline Ornamental fountains & 2.75 & 1.4 & 2.33 & 1.278 & 3.91 & 1.177 & 4.1 & 1.325 \\
Trees and flowers & 4.25 & 0.754 & 3.81 & 1.182 & 4.13 & 1.007 & 3.96 & 1.217 \\
Beautiful landscape design & 3.76 & 0.952 & 3.38 & 1.103 & 3.67 & 1.045 & 3.77 & 1.019 \\
Signs and information & 3.71 & 1.382 & 2.09 & 1.126 & 4.31 & 0.781 & 4.53 & 0.709 \\
Light coloured street furniture & 2.13 & 1.33 & 2.05 & 1.199 & 2.72 & 1.336 & 2.67 & 1.333 \\
Lighting & 3.51 & 1.377 & 3.66 & 1.425 & 4.13 & 1.027 & 4.18 & 1.309 \\
Shade & 4.57 & 0.676 & 4.29 & 0.945 & 4.25 & 0.886 & 4.41 & 0.803 \\
Flowing water & 3.84 & 1.12 & 4.16 & 1.009 & 4.27 & 0.809 & 4.43 & 0.946 \\
Places to sit and relax & 4.2 & 0.978 & 3.87 & 1.197 & 3.92 & 1.042 & 3.76 & 1.273 \\
\hline
\end{tabular}

Taking each factor at a time, looking at the means from Table 5, we can see that fountains score on average much higher in Chehelsotoon and Bagh-e-Phin than for Mellat 
or Jamshidieh (where they are below average): the traditional parks, with water features as key defining elements are preferred here (although the standard deviations show a fairly wide range). For the presence of trees and flowers there is not much difference overallthese are important feature in any park, as would be expected. A beautiful landscape design-a somewhat difficult and subjective factor to interpret perhaps-is just above average for all parks, with a relatively low standard deviation. Signs and information are rated much more highly for the two traditional parks than the two modern onespossibly because visitors wish to understand the historical features of these parks, which are interpreted using signs on-site. The aspect of light coloured street furniture is rated fairly low for all parks and with a similar standard deviation-clearly not an important design factor despite being listed by experts in the Delphi study. The presence of lighting is rated higher for the traditional parks than for the modern ones-despite the fact that they close at $6 \mathrm{pm}$ while the modern ones stay open until the late evening. However, the traditional parks have special lighting effects to pick out the architecture for example, which may account for this. The importance of providing shade is clear-the means are all over 4 , closer to 5 in some cases and with lower standard deviations than for several other factors. The presence of ornamental fountains stands out as the most important factor for the modern parks, though equal to others for the traditional parks, where ornamental fountains are as if not more important. Flowing water is also seen as more important in the traditional parks-although closely followed by Jamshidieh. Thus water as a key element seems to stand out as a more defining feature in the traditional parks, even though the modern parks each include large water features. Finally, places to sit and relax score above the middle range of the rating scale, with not much to choose among the parks.

\section{Accessibility}

This section looks at the relative importance given by the respondents to accessibility to the parks and gardens by various means. Table 6 presents the Pearson chi square test for the five items. The results revealed that there was a significant difference across the four parks. The greatest differences were, in descending order, park usability in the daytime and at night; access to the park on foot; access to the park by bicycle; access to the park by car; and access to the park by public transport. The means of the Likert scale preference scores (1-5 scale for each) are presented together with the standard deviations (Table 7). Thus, scores above 3 are in the higher range of average preference and scores below 3 in the lower range.

Table 6. Results of the Pearson chi-square test on the factors comprising the key accessibility elements.

\begin{tabular}{ccccc}
\hline Accessibility & Pearson Chi-Square & df & $p$ Value & N \\
\hline Access to the park by bicycle & 86.586 & 12 & $<0.01$ & 1118 \\
Access to the park by car & 78.946 & 12 & $<0.01$ & 1091 \\
Access to the park on foot & 116.385 & 12 & $<0.01$ & 1103 \\
Park usability in the daytime and at night & 154.369 & 12 & $<0.01$ & 1109 \\
Access to the park by public transport & 76.886 & 12 & $<0.01$ & 1148 \\
\hline
\end{tabular}

Table 7. Means and standard deviations for each of the accessibility factors compared across each of the four sample parks.

\begin{tabular}{ccccccccc}
\hline Accessibility & \multicolumn{2}{c}{ Mellat } & \multicolumn{2}{c}{ Jamshidieh } & \multicolumn{2}{c}{ Bagh-e-Phin } & \multicolumn{2}{c}{ Chehelsotoon } \\
\hline & Mean & SD & Mean & SD & Mean & SD & Mean & SD \\
\hline Access to the park by bicycle & 3.24 & 1.329 & 2.93 & 1.25 & 2.97 & 1.401 & 3.6 & 1.44 \\
Access to the park by car & 3.47 & 1.175 & 3.45 & 1.252 & 3.26 & 1.191 & 3.73 & 1.329 \\
Access to the park on foot & 3.67 & 0.939 & 3.71 & 1.076 & 3.68 & 1.122 & 4.12 & 1.038 \\
Park usability in the daytime and at night & 3.95 & 1.129 & 3.72 & 1.331 & 4.1 & 0.84 & 4.36 & 0.948 \\
Access to the park by public transport & 3.57 & 1.234 & 3.29 & 1.286 & 3.51 & 1.146 & 3.82 & 1.29 \\
\hline
\end{tabular}


From the means and standard deviations in Table 7 we can see that for the factor of access to the park by bicycle, the means hover around the mid-range of 3 in the 1-5 Likert scale of preference, with high standard deviations, suggesting that there is not much agreement here. This is perhaps not surprising given that cycling is not yet a major form of transport in Iran and that two of the parks (Jamshidieh and Bagh-e-Phin) are located well away from where a lot of visitors live. Jamshidieh is not suitable for cycling because it is located in hilly, rocky topography and Bagh-e-Phin is located in a religious city, where people live in a more traditional manner. The rating for the importance of access by car to the parks is generally similar and just above the mid-range of the scale but with a similar standard deviation as for access by bicycle. The importance of accessibility of foot scores is somewhat higher than that for car or bicycle, especially so for Chehelsotoon-which also happens to be the one park located in the centre of the city where foot access is much easier than for the rest. The aspect of usability at both daytime and night reveals rather odd results - this is rated higher for the two traditional parks which are closed to visitors at $6 \mathrm{pm}$ while the modern parks are used until well into the late evening. Accessibility by public transport is rated as above the mid-range of scores although with a larger standard deviation than for some other factors. This could be because public transport connections are not well-developed and are unreliable to these specific parks.

\section{Cultural Facilities, Activities and Services}

This section looks at the range of different cultural facilities, activities and services which are frequently available in Iranian parks. Table 8 presents the results of the Pearson chi-square test for these seven aspects. These are ranked in the descending order of: access to media, availability of libraries and study facilities, the opportunity to paint or pursue art activities and the availability of souvenir or handicraft shops or stalls.

Table 8. Results of the Pearson chi-square test on the factors comprising the key aspects of cultural activities and services.

\begin{tabular}{cccccc}
\hline Cultural Activity & $\begin{array}{c}\text { Pearson } \\
\text { Chi-Square }\end{array}$ & df & $p$ Value & N \\
\hline Access to media & 164.379 & 12 & $<0.01$ & 1145 \\
Availability of libraries and study facilities & 120.533 & 12 & $<0.01$ & 1142 \\
Opportunity to paint or pursue art activities & 103.426 & 12 & $<0.01$ & 1145 \\
The availability of souvenir or handicraft shops or stalls & 94.240 & 12 & $<0.01$ & 1139 \\
\hline
\end{tabular}

From the means and standard deviations presented in Table 9 we can see that access to media is seen as somewhat important by respondents in Mellat and Chehelsotoon but less so in the others (although with wide standard deviations). The availability of libraries and study facilities is not seen as being important to visitors to the modern parks and only of moderate interest to those visiting the historic parks-perhaps if those facilities offer information on the history of those places. Nowhere is there any real importance given to the opportunity to pursue artistic activities while souvenir or craft shops or stalls-despite them being common sights - are also not considered to be important except to a slight degree in Mellat park where there are the most of such kiosks.

Table 9. Means and standard deviations for each of the cultural activity factors compared across each of the four sample parks.

\begin{tabular}{|c|c|c|c|c|c|c|c|c|}
\hline \multirow[t]{2}{*}{ Accessibility } & \multicolumn{2}{|c|}{ Mellat } & \multicolumn{2}{|c|}{ Jamshidieh } & \multicolumn{2}{|c|}{ Bagh-e-Phin } & \multicolumn{2}{|c|}{ Chehelsotoon } \\
\hline & Mean & SD & Mean & SD & Mean & SD & Mean & SD \\
\hline Access to media & 3.57 & 1.26 & 2.66 & 1.177 & 2.71 & 1.327 & 3.51 & 1.387 \\
\hline The availability of libraries and study facilities & 2.82 & 1.291 & 2.42 & 1.3 & 3.05 & 1.224 & 3.12 & 1.545 \\
\hline The opportunity to paint or pursue art activities & 2.82 & 1.3 & 2.55 & 1.247 & 2.87 & 1.283 & 2.46 & 1.521 \\
\hline The availability of souvenir or handicraft shops or stalls & 3.52 & 1.275 & 2.77 & 1.183 & 3.05 & 1.293 & 3.36 & 1.293 \\
\hline
\end{tabular}




\section{Safety and Security}

This section covers the category of factors related to the safety and security, especially against crime, of the four sampled parks. The results of chi-square test (Table 10) revealed that there was a significant difference across all four parks in the descending order of physical safety of spaces, facilities and equipment, having a police presence at the park and there being an overall feeling of security and calmness.

Table 10. Results of the Pearson chi-square test on the factors comprising the key aspects of safety and security.

\begin{tabular}{ccccc}
\hline Safety and Security & $\begin{array}{c}\text { Pearson } \\
\text { Chi-Square }\end{array}$ & df & $p$ Value & N \\
\hline Physical safety of spaces, facilities and equipment & 105.308 & 12 & $<0.01$ & 1133 \\
Having a police presence at the park & 76.269 & 12 & $<0.01$ & 1148 \\
An overall feeling of security and calmness & 61.31 & 12 & $<0.01$ & 1142 \\
\hline
\end{tabular}

The means and standard deviations for the factors related to safety and security in Table 11 show some differences. Aspects of physical safety are perceived as being important in all parks, slightly more so in Mellat and Chehelsotoon. Having a police presence is seen as less important than an overall feeling of safety and calmness which applies to all parks but stands out more so—-with a smaller standard deviation—-for Chehelsotoon.

Table 11. Means and standard deviations for each of the cultural activity factors compared across each of the four sample parks.

\begin{tabular}{|c|c|c|c|c|c|c|c|c|}
\hline \multirow[t]{2}{*}{ Accessibility } & \multicolumn{2}{|c|}{ Mellat } & \multicolumn{2}{|c|}{ Jamshidieh } & \multicolumn{2}{|c|}{ Bagh-e-Phin } & \multicolumn{2}{|c|}{ Chehelsotoon } \\
\hline & Mean & SD & Mean & SD & Mean & SD & Mean & SD \\
\hline Physical safety of spaces, facilities and equipment & 4.23 & 0.953 & 3.92 & 1.092 & 3.90 & 1.012 & 4.04 & 1.129 \\
\hline Having a police presence at the park & 3.76 & 1.135 & 3.59 & 1.309 & 3.65 & 1.317 & 3.69 & 1.39 \\
\hline An overall feeling of security and calmness & 4.58 & 0.781 & 4.27 & 1.036 & 4.32 & 1.177 & 4.59 & 0.76 \\
\hline
\end{tabular}

Spiritual Factors

This section looks at a category of perceptual factors broadly defined as covering spiritual aspects. The results of the chi square test (Table 12) revealed that there was a significant difference across the four parks in the descending order of obtaining inspiration hearing broadcast music, being able to feel less stressful, feeling revitalised, being able to leave cares behind and being away from crowds.

Table 12. Results of the Pearson chi-square test on the factors comprising the key aspects of spirituality.

\begin{tabular}{ccccc}
\hline Spirituality & Pearson Chi-Square & df & $p$ Value & N \\
\hline Obtaining inspiration & 141.738 & 12 & $<0.01$ & 1116 \\
Hearing broadcast music & 112.024 & 12 & $<0.01$ & 1124 \\
Being able to leave cares behind & 62.228 & 12 & $<0.01$ & 1131 \\
Being able to feel less stressful & 108.274 & 12 & $<0.01$ & 1121 \\
Feeling revitalised & 72.165 & 12 & $<0.01$ & 1100 \\
Being away from crowds & 59.464 & 12 & $<0.01$ & 1112 \\
\hline
\end{tabular}

The means and standard deviations presented in Table 13 show that obtaining inspiration is somewhat important-Chehelsotoon stands out from the others in this regard, and to some extent also in Mellat. Hearing broadcast music is also somewhat popular, also more so in Mellat (where the park is full of activities and people having fun) and Chehelsotoon. However, these two aspects are overshadowed by the importance placed on the four aspects associated with feelings, with revitalisation standing out from these for 
all parks except Bagh-e-Phin. This shows that many of the benefits associated with using parks to offset the stresses of modern life are also seen as important in Iran.

Table 13. Means and standard deviations for each of the spiritual factors compared across each of the four sample parks.

\begin{tabular}{ccccccccc}
\hline Accessibility & \multicolumn{2}{c}{ Mellat } & \multicolumn{2}{c}{ Jamshidieh } & \multicolumn{2}{c}{ Bagh-e-Phin } & \multicolumn{2}{c}{ Chehelsotoon } \\
\hline & Mean & SD & Mean & SD & Mean & SD & Mean & SD \\
\hline Obtaining inspiration & 3.70 & 1.125 & 3.51 & 1.256 & 3.30 & 1.296 & 3.97 & 1.233 \\
Hearing broadcast music & 3.96 & 1.148 & 3.59 & 1.241 & 3.23 & 1.334 & 3.94 & 1.31 \\
Being able to leave cares behind & 4.20 & 0.988 & 4.12 & 0.900 & 3.99 & 1.002 & 4.36 & 0.933 \\
Being able to feel less stressful & 4.04 & 1.122 & 3.82 & 1.258 & 3.76 & 1.031 & 4.35 & 0.952 \\
Feeling revitalised & 4.46 & 0.799 & 4.21 & 0.947 & 3.88 & 1.092 & 3.95 & 1.185 \\
Being away from crowds & 4.31 & 0.935 & 4.11 & 1.136 & 3.86 & 1.282 & 4.18 & 1.217 \\
\hline
\end{tabular}

Recreational Opportunities and Facilities

This section looks at the relative importance of a category of factors grouped around opportunities for recreation activities and associated facilities. The results of the chisquare test (Table 14) revealed that there was a significant difference across the four parks in the following descending order: opportunities to buy food; having places for children to play and have fun; facilities for exercise; opportunities for group and social activities; opportunities to play informal games; having the park useable by older people; opportunities to cycle; opportunities for walking; opportunities to eat; opportunities to spend time with the family; opportunities for spending time with friends; presence of playing fields.

Table 14. Results of the Pearson chi-square test on the factors comprising the key aspects of recreational opportunities and facilities.

\begin{tabular}{|c|c|c|c|c|}
\hline Recreational Opportunities and Facilities & Pearson Chi-Square & df & $p$ Value & $\mathbf{N}$ \\
\hline Having the park useable by older people & 71.246 & 12 & $<0.01$ & 1151 \\
\hline Having places for children to play and have fun & 130.405 & 12 & $<0.01$ & 1154 \\
\hline Opportunities to cycle & 65.87 & 12 & $<0.01$ & 1136 \\
\hline Opportunities to play informal games & 79.322 & 12 & $<0.01$ & 1151 \\
\hline Facilities for exercise & 90.404 & 12 & $<0.01$ & 1139 \\
\hline Opportunities for walking & 65.054 & 12 & $<0.01$ & 1154 \\
\hline Playing field & 47.076 & 12 & $<0.01$ & 1106 \\
\hline Opportunities for group and social activities & 88.729 & 12 & $<0.01$ & 1142 \\
\hline Opportunities to eat & 60.579 & 12 & $<0.01$ & 1148 \\
\hline Opportunities to buy food & 134.107 & 12 & $<0.01$ & 1151 \\
\hline Opportunities to spend time with the family & 56.923 & 12 & $<0.01$ & 1151 \\
\hline Opportunities for spending time with friends & 54.956 & 12 & $<0.01$ & 1154 \\
\hline
\end{tabular}

The means and standard deviations presented in Table 15 show that there are some wider differences among these factors than for many of the other categories. For all the activities associated with recreation and play, the traditional parks score much lower-it is clear that these are not seen as appropriate in such parks or else there is no specific provision for them. The same applies when scoring for the importance of buying food or being able to eat. For all the more social types of activities the differences are much less between all the parks and factors such as spending time with family or friends are rated the highest on average. One aspect which stands out is the much lower score given to the usability by older people at Jamshidieh, which has many steep paths in its hilly terrain. 
Table 15. Means and standard deviations for each of the factors of recreational opportunities and facilities compared across each of the four sample parks.

\begin{tabular}{|c|c|c|c|c|c|c|c|c|}
\hline \multirow[t]{2}{*}{ Recreational Opportunities and Facilities } & \multicolumn{2}{|c|}{ Mellat } & \multicolumn{2}{|c|}{ Jamshidieh } & \multicolumn{2}{|c|}{ Bagh-e-Phin } & \multicolumn{2}{|c|}{ Chehelsotoon } \\
\hline & Mean & SD & Mean & SD & Mean & SD & Mean & SD \\
\hline Having the park usable by older people & 4.08 & 0.997 & 2.83 & 1.321 & 3.8 & 1.513 & 3.78 & 1.395 \\
\hline Having places for children to play and have fun & 4.33 & 0.739 & 2.63 & 1.569 & 2.09 & 1.225 & 2.1 & 1.219 \\
\hline Opportunities to cycle & 4.3 & 0.803 & 2.71 & 0.992 & 2.03 & 1.525 & 2.24 & 1.07 \\
\hline Opportunities to play informal games & 4.28 & 0.957 & 3.35 & 1.143 & 2.41 & 0.979 & 2.6 & 1.219 \\
\hline Facilities for exercise & 3.99 & 1.067 & 3.13 & 1.191 & 2.36 & 1.01 & 2.16 & 1.059 \\
\hline Opportunities for walking & 4.26 & 0.793 & 3.89 & 0.918 & 3.55 & 1.101 & 3.72 & 1.095 \\
\hline Playing fields & 4.04 & 1.12 & 3.82 & 1.258 & 2.13 & 0.947 & 2.11 & 0.953 \\
\hline Opportunities for group and social activities & 3.84 & 1.244 & 3.9 & 1.322 & 3.06 & 1.227 & 3.15 & 1.539 \\
\hline Opportunities to eat & 4.2 & 0.887 & 3.74 & 1.117 & 2.74 & 1.15 & 2.84 & 1.269 \\
\hline Opportunities to buy food & 4.31 & 0.729 & 3.94 & 1.046 & 2.78 & 1.022 & 2.86 & 1.217 \\
\hline Opportunities to spend time with the family & 4.03 & 1.132 & 3.95 & 1.138 & 4.05 & 1.047 & 4.16 & 1.162 \\
\hline Opportunities for spending time with friends & 4.2 & 1.097 & 4.03 & 0.778 & 4.13 & 0.916 & 4.4 & 0.741 \\
\hline
\end{tabular}

\subsection{Testing for the Components Which Predict Successful Parks}

The results of the factor analysis are presented in Table 17 and show that from the 42 existing items, 11 major components can be identified.

From Table 17 we can interpret it as follows-each descending component number explains a proportion of the variance within the data and combines variables with a degree of interdependency into single (unobserved-i.e., not directly visible in the data as a whole) latent variables. The predictive value of the identified latent variable decreases as we move down the table, since it explains less of the variance (although they are still relevant latent variables). These are described and named (for better understanding and future reference) below. In doing this we looked at the combination of the variables contributing to the factor and we thus tried to find a simple yet evocative term to describe each.

The first set of factors with the most components is 'having fun and enjoying oneself'with children, with music, eating, playing games and taking exercise. This is the latent variable which can be recognised as being typical for visiting an urban park. The second set comprises aspects associated with there being 'no barriers to using the park'-barriers preventing getting there, feeling secure and finding one's way about-important aspects often highlighted in the literature. The third set is associated with 'leaving one's cares behind'being able to stroll, feel revitalised and that one's possessions are safe-an important aspect in enabling visitors to enjoy a visit without feeling anxious. The fourth set can be termed 'relaxing in the presence of natural beauty' - water, nature, trees and flowers, lighting and a beautiful design - all features that are also important in providing a contrast with urban life and which are key aspects featured in the literature. Fifth, with fewer components, is 'strolling and browsing' - away from other people, looking at craft souvenirs-a minor activity. Next, the sixth set is 'being with my family in nature'. The seventh set can be termed 'being social and creative' - using the park furniture to be in a group and maybe eating or doing art or other creative activities. The eighth set is a single factor of 'being inspired' while the ninth is 'sitting in the shade with friends'. The tenth is a single factor of 'using the library' while the final set of two can be termed a 'safe place to go for a trip'-combining car access with police presence. These last six factors are less important or of interest to a smaller number of visitors. 


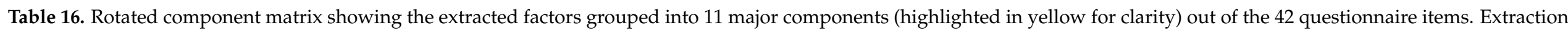
method: principal component analysis. Rotation method: Varimax with Kaiser Normalization. a. Rotation converged in 15 iterations.

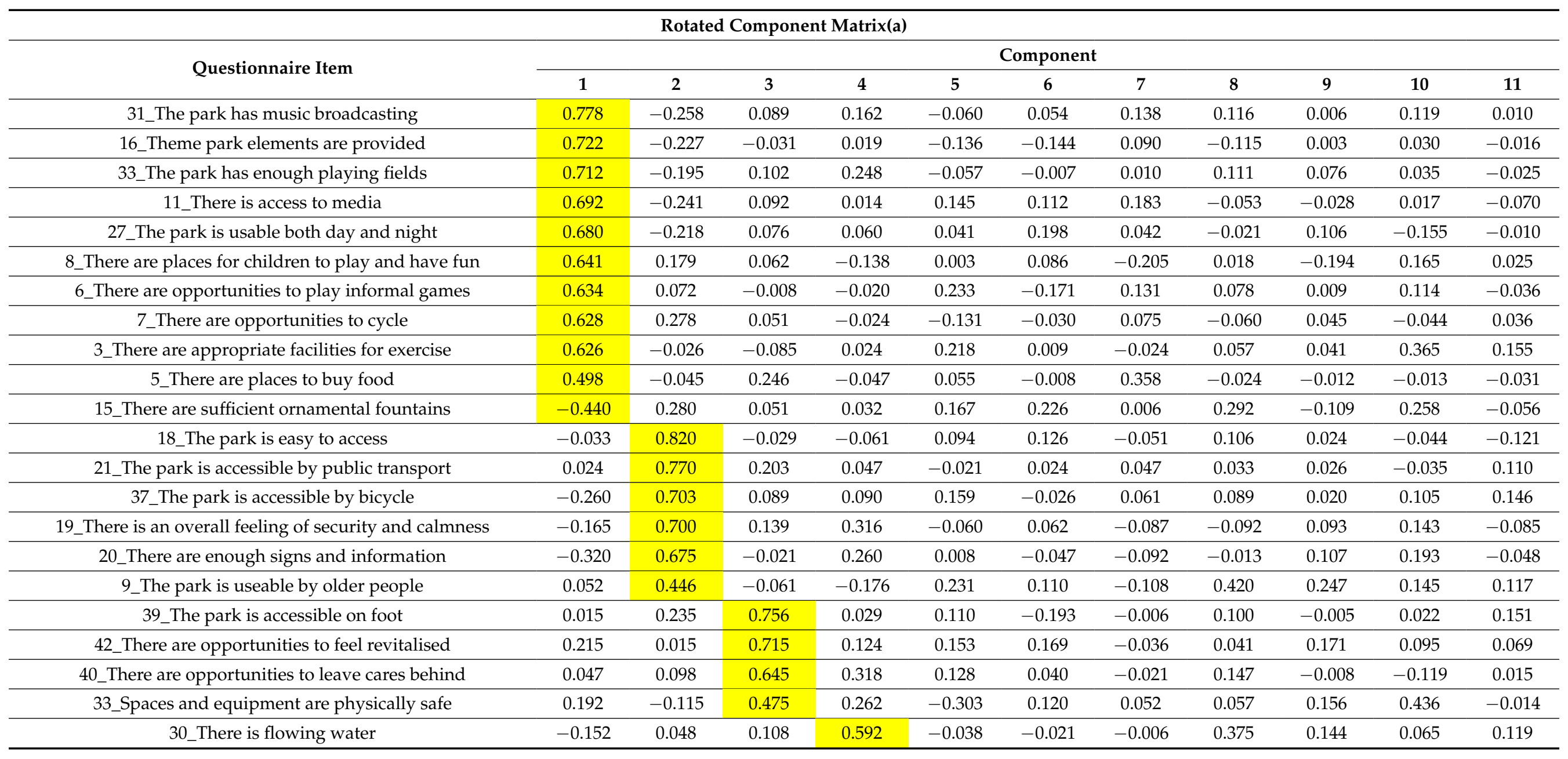




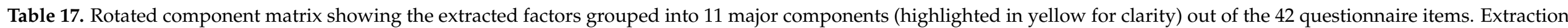
method: principal component analysis. Rotation method: Varimax with Kaiser Normalization. a. Rotation converged in 15 iterations.

\begin{tabular}{|c|c|c|c|c|c|c|c|c|c|c|c|}
\hline \multicolumn{12}{|c|}{ Rotated Component Matrix(a) } \\
\hline \multirow{2}{*}{ Questionnaire Item } & \multicolumn{11}{|c|}{ Component } \\
\hline & 1 & 2 & 3 & 4 & 5 & 6 & 7 & 8 & 9 & 10 & 11 \\
\hline 1_There are appropriate places for sitting and relaxing & 0.101 & 0.121 & 0.174 & 0.575 & 0.039 & -0.033 & 0.121 & 0.020 & 0.027 & 0.221 & -0.118 \\
\hline 17_There are enough trees and flowers & 0.135 & 0.240 & 0.175 & 0.573 & 0.164 & 0.271 & 0.012 & -0.077 & -0.004 & 0.157 & -0.140 \\
\hline 29_Being able to feel less stressful when in the park & 0.092 & 0.137 & 0.086 & 0.496 & 0.261 & -0.054 & -0.165 & -0.017 & 0.047 & -0.238 & 0.198 \\
\hline 25_There is enough lighting for when it is dark & 0.199 & -0.070 & 0.078 & 0.451 & 0.054 & 0.334 & -0.075 & 0.004 & -0.026 & -0.229 & 0.272 \\
\hline 24_The park has a beautiful landscape design & -0.016 & 0.230 & 0.185 & 0.292 & 0.072 & 0.215 & 0.235 & 0.193 & 0.216 & 0.007 & 0.248 \\
\hline 41_There are opportunities to be away from crowds & -0.006 & 0.026 & 0.135 & 0.146 & 0.673 & -0.006 & 0.134 & 0.177 & 0.179 & 0.005 & 0.126 \\
\hline 22_Souvenir or handicraft shops or stalls are available & 0.047 & 0.203 & 0.193 & 0.107 & 0.566 & 0.284 & -0.171 & -0.025 & 0.062 & 0.011 & -0.055 \\
\hline 2_There are opportunities for walking & 0.232 & 0.133 & 0.310 & 0.139 & 0.341 & 0.341 & 0.036 & -0.265 & 0.099 & 0.090 & 0.122 \\
\hline 14_It is possible to listen to and to observe nature & -0.084 & 0.053 & -0.105 & 0.002 & 0.088 & 0.703 & 0.126 & -0.039 & -0.044 & 0.006 & 0.016 \\
\hline 35_There are opportunities to spend time with family & -0.058 & 0.108 & 0.318 & 0.130 & 0.036 & 0.512 & -0.049 & 0.315 & 0.171 & 0.089 & -0.117 \\
\hline 23_Street furniture is light in colour & -0.150 & 0.040 & 0.155 & 0.187 & 0.223 & -0.018 & -0.557 & -0.171 & 0.025 & 0.104 & -0.060 \\
\hline 13_There is the opportunity to paint or pursue art activities & 0.228 & -0.032 & 0.039 & 0.226 & 0.100 & 0.294 & 0.543 & -0.039 & 0.047 & 0.046 & 0.200 \\
\hline 12_There are opportunities for group and social activities & 0.219 & -0.120 & 0.086 & 0.014 & 0.398 & 0.183 & 0.402 & -0.184 & 0.185 & 0.285 & 0.088 \\
\hline 34_Being able to obtain inspiration & 0.072 & 0.072 & 0.217 & 0.146 & 0.029 & -0.006 & 0.041 & 0.774 & -0.020 & -0.067 & 0.057 \\
\hline 28_There is enough shade & 0.117 & 0.138 & 0.048 & 0.108 & 0.066 & 0.091 & 0.028 & -0.183 & 0.735 & -0.121 & 0.092 \\
\hline 36_There are opportunities to spend time with friends & -0.056 & 0.065 & 0.126 & 0.026 & 0.212 & -0.084 & 0.016 & 0.290 & 0.681 & 0.100 & -0.069 \\
\hline 10_There is availability of libraries and study facilities & 0.212 & 0.269 & 0.019 & 0.089 & 0.078 & 0.005 & -0.060 & -0.035 & -0.071 & 0.656 & 0.021 \\
\hline 38_The park accessible by car & -0.035 & -0.018 & 0.095 & 0.020 & 0.120 & -0.058 & 0.171 & 0.046 & -0.019 & -0.019 & 0.780 \\
\hline 26_There is a police presence at the park & -0.028 & 0.151 & 0.179 & 0.027 & -0.161 & 0.224 & -0.311 & 0.046 & 0.253 & 0.273 & 0.450 \\
\hline
\end{tabular}




\subsection{Testing for the Differences between the Two Types of Parks}

In order to test for differences between the park types, Figure 3 shows the NMDS ordination plot generated by the process described in the methods section.

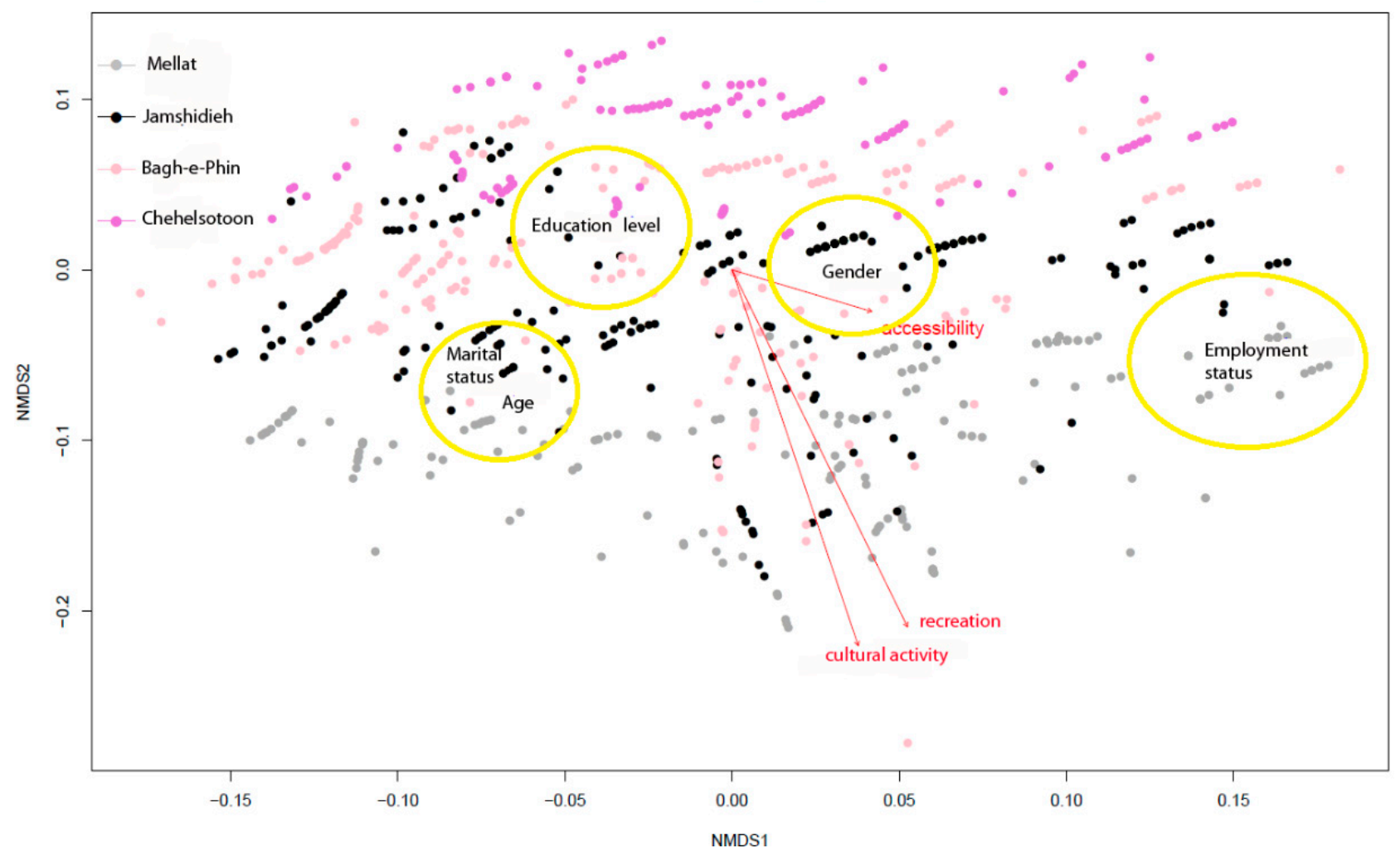

Figure 3. NMDS ordination plot of the 920 questionnaires collected from the four parks (Mellat, Jamshidieh, Bagh-ePhin and Chehelsotoon) with fitted aggregated questionnaires and variable clusters 'accessibility', 'cultural activity' and 'recreation' together with the key demographic variables associated with the preferences. Yellow circles were added to identify and represent regions in the plot where there are tendencies for each visitor to be associated with specific parks. Red arrows represent the trends of association of the three significantly correlated groups of factors to the visitor's preference for specific parks.

For reading the plot it is necessary to remember that each point represents an individual respondent and behind these points are all the answers given in the questionnaire survey. The yellow circles (added by the authors for clarity) represent regions where there is a stronger tendency for each of the named demographic variables to be associated with the visitors to each park.

What we can thus interpret from the results of the NMDS analysis is as follows. For the demographic variables we can see a stronger association between gender and a preference for the modern parks, especially Jamshidieh, since there is a region at this point highlighted with a yellow border. For occupational status, there is also a tendency for preference for the modern parks, this time focused on Mellat as well as, to some extent, Jamshidieh, also enclosed by a yellow border. For marital status as well as age, there is also a further region on the plot related to the two modern parks, Mellat and Jamshidieh. Only when we look at educational level do we see a stronger preference associated with a region on the plot with the traditional parks of Bagh-e-Phin and Chehelsotoon. Turning to the three significant sets of factors: recreation, accessibility and cultural activities, in the plot there are three directional arrows, one for each, which show the tendency for the strength of association between them and the parks. In the case of accessibility, it is not a very strong trend but it is more for the modern parks than the traditional ones, while for the factors of recreational 
value and cultural activity the trends are strong and in the same general direction-clearly focused on the modern parks.

\section{Discussion}

We can see from the results that of the many factors we identified from the literature and in our small Delphi survey-factors that tend to be universal-most of these scored at a level of 'agree' or 'strongly agree' (scores 4 or 5 on the Likert scale) in all parks surveyed. In this regard the needs of the contemporary urban population of Iran are not very different from anywhere else. When considering who uses the parks, from the analysis of the characteristics of the respondents in Table 2, we can see that there was a large majority of young single men in all parks and fewer women or married people. We are confident that the sampling procedure used and the large sample size correctly picked up the balance of users over the period of data collection. Thus, this being the case, there are several aspects that can be taken into account-first, to see why there is this imbalance-which might be associated with cultural and other aspects. The problem of lower uses of parks by women in Iran has already been noted and other studies have identified the need to pay more attention to their needs and to provide suitable supporting structures [38]. This information can help decision-makers to plan according to people's needs and expectations. As noted in other studies, it is also necessary to know for whom a park is targeted, requiring data about, for example, the age, gender, ethnicity and socio-economic status of the users, as well as something of the demand for the various activities programmed there [9]. Rezazadeh [54] considers that it is necessary for politicians and park programmers to involve women's interests with increasing gender awareness in order to resolve this imbalance in the pattern of park users. Our survey goes some way to identifying the characteristics of users to two different types of parks-the modern and traditional, where there are both similarities and differences in the profiles.

We can compare the results of the park-specific items with the factor analysis. The loading under the first important factors is of a range of attributes we have termed under the heading of 'having fun and enjoying oneself' and the variables included in this factor were also generally evaluated at a mean above 3.5 in the scale of importance as rated by the respondents for all parks but especially for Mellat and Jamshidieh, the contemporary parks. This highlights the importance of considering this kind of recreation in the social life of the Iranian people. These results support those previously reported [23,24], which stress the role of green spaces in increasing inhabitants' well-being and physical health. For this reason, urban parks should be used to promote the well-being of the Iranian urban society and increase the liveability of cities [46].

The second factor which we have named 'no barriers to using the park' is also very important-one of the issues commonly identified in the literature concerns inequity of access, barriers of various sorts-physical or social, for example. These factors were also generally highly rated by respondents-apart from accessibility by bicycle-which is an aspect of transport which needs greater development in Iran compared to many other countries.

The third factor 'leaving one's cares behind' focuses on mental well-being. In countries such as Iran, in which urban dwellers (in common with many other countries but with specific aspects here) face many mental and physical pressures, people ought to be using parks and green spaces more than they do. There is some evidence that Iranians attach a special value for nature [55] and would like to spend their leisure time outside of their residences in parks, in order to feel happy. However, earlier studies by the authors have shown that park availability is not equally distributed $[9,56]$. The aspects included in this analysis were also ones rated highly - especially that of feeling revitalised, which was one of the highest scored aspects overall.

Relaxing in the presence of natural beauty is the next factor and the last one to be composed of a number of aspects. The fact that this comes as the fourth major factor is interesting - it seems to show that while important, it is something of a bonus in addition to 
the earlier and more significant factors. This was also reflected in the scores where aspects such as trees and flowers, lighting or beautiful design were not as highly rated compared with some others, and where there were some differences between the two types of park.

The rest of the factors are based on fewer aspects and explain much less of the overall variance within the data and they reveal some lesser characteristics associated with the parks and their visitors-ones which are perhaps important to some people but not generally.

According to these results, a majority of park users focus on those aspects we have named 'having fun and enjoying oneself' - 'being with friends', 'spending time with family' and 'walking' being among the most important aspects contributing to this. This emphasises the importance of the social life for the Iranian people, as Dastmalchian et al. and Fakuhi noted [ 57,58$]$, reflecting the strong family orientated living structures. In addition, while some younger people spend less time with their family and may spend their leisure time individually, couples and couples with children spend more of their leisure time together. This is consistent with Bedimo-Rung et al. [20], emphasising the role of urban parks as places for people to socialise with their families and friends.

Regarding the aspect of physical exercise which is also contained within the factors for 'having fun and enjoying oneself', as Mozaffari et al. [59] noted, sport and exercise only forms a moderate component of use of public spaces in Iran. This latter finding reflects Ghandehari et al. [22], who found that a majority of Iranian park users preferred less intensive physical activity (recreational walking) and proposed that more needs to be done to encourage higher intensities of exercise in parks.

The 'having fun and enjoying oneself' factor has the highest inter-correlation and accounts for the most variance. The second factor, of 'no barriers to using the park' also includes the general feeling of safety which is important as Iranian people like to use parks at night when it is cooler in summer-especially younger people $[9,38,56]$. As Salehifard et al. note [8], for improving the quality of urban parks to increase public satisfaction, park facilities can be an effective guide.

The results of the NMDS analysis showed quite clear differences for the main groups of elements extracted from the questionnaire (correlated via the factor analysis using the 'envfit' function with high enough statistical significance, and then fed into the NMDS) referred to as accessibility, cultural activity and recreation. We can see that there is a tendency for being a higher preference among different demographic groups for the modern parks. This accords with the results of the factor analysis-where the first three or so factors align well with the NMDS factors and are also associated with aspects that do not fit with what can be done in the traditional parks due in part to their historical character and design. This is interesting, because when they were first built they provided the elites at the time opportunities for 'having fun and enjoying oneself' but the forms of enjoyment were very different to nowadays. The overall status of 'cultural elements' in the sample parks was rated fairly low amongst the scores by the respondents in our survey.

It should be noted that the two historical parks are also museums and charge an entrance fee as well as closing earlier than the modern parks. This did not seem to affect the general preferences for the factors tested in the questionnaires. However, the tendency shown in the NMDS plot was for their visitors to be better educated. We might infer that this reflects the museum status. Thus we should be somewhat circumspect in terms of what we can conclude from this as the fact that there is an entrance fee may have affected the results, presenting barriers to access by some people. Within the data on preferences for specific factors there was some difference between the park types but it was not very pronounced apart from the presence of ornamental fountains, flowing water and information signs (relevant because they are museums). While there is a preference overall for the contemporary parks we cannot infer anything more specific about the contribution of Persian traditional style here, apart, perhaps, for the emphasis on water which was highlighted by Beshbahani and Naima [42,44] (bearing in mind that such gardens served rather different functions from today's parks). 
The question remains - if the traditional parks as a whole do not answer the contemporary needs of Iranians then are there some specific elements that might be used, with reinterpretation in newer parks? As Shahcheraghi, [45] notes, one of the most important reasons why Persian (Iranian) gardens have remained attractive over the centuries is the focus on activating all the senses (sight, hearing, smell, touch and taste) where the role of water-in part to provide a sound to counteract external noise-was also important. Thus, we can propose that when modern designers work on a new park or reconstruction of an existing one, they might consider giving attention on harnessing this sensory concentration while reacting to the kinds of preferences we have uncovered in this research. Filling the parks with cultural centres and activities is not so important-those who were educated and preferred this visited the traditional parks.

Therefore, sufficient knowledge about the user groups and their cultural situation and needs in interaction with the environment can result, in accordance with the research of Sharefi [37] in improving the functions and the environmental balance, stability and sustainability and makes a lively space with sufficient social security. All of these statements indicate the importance of public parks, therefore urban planners should consider all these elements in the planning and designing of parks in metropolitan area. For a deeper understanding of how to reinterpret the best that Persian or Iranian traditions have to offer, we should study their historical roots [13].

\section{Limitations and Further Research}

The research was based on a study of four parks-two in Tehran which were built immediately before the Islamic revolution in the time of the last Shah, when westernising tendencies were dominant, and two much older historical Persian gardens. To that extent, the parks are not representative of all parks in Tehran or Iran. While we tried to test the differences between contemporary and traditional parks, the fact that the latter are also museums and charge an entrance fee could have affected the results to some extent. If it is considered interesting for possible further research, then a more focused look at the differences could be undertaken. For example, by designing the survey to ask questions about preferences for factors related to parks in general and then, separately about the specific park being visited, it may be easier to extract results to determine the differences as well as similarities more clearly than we were able to do. However, the work is intended to complement other work carried out by the authors which looked at a wider sampleincluding the two Tehran parks considered here [9]. Nevertheless, if the conclusions we have drawn are to be more generalised, similar research would be invaluable if carried out using similar methods on more parks in more cities. One shortcoming is that those who do not visit the parks were excluded from the survey-which would have had to follow a different design. The research was undertaken some years before the current Covid-19 pandemic and it could be expected that perceptions of the value of parks could have changed as a result of people being unable to visit them so easily.

As the possibilities of a single survey are limited, we suggest that further research could explore additional factors, including more design-related aspects such as layout, proportion of open to enclosed spaces and formality or informality of style.

\section{Conclusions}

The research reported in this paper asked the following research question:

- What are the Iranian people's current needs and priorities for a good park and to what extent do they vary depending on whether a park is contemporary or traditional?

The study revealed a number of factors that emerged from the collection of aspects rated as more-or-less important by the respondents of which three key factors emerged which we named as 'having fun and enjoying oneself', there being 'no barriers to using the park' and 'leaving one's cares behind', followed by a fourth, less significant one, 'relaxing in the presence of natural beauty'. The aspects comprising these factors are thus those that should be the focus of park designers in future, while the other factors, while not being ignored, 
can be given less prominence. We suggest therefore, that planners take the evidence we have presented here and use it to evaluate any particular park in terms of what it offers-or should offer-in this respect. This is important given the problems of quality of many parks in Tehran as revealed in previous research [9]

In relation to the second part of the research question, we can conclude that on the whole the modern parks were found to be generally preferred over the traditional ones-with some provisos in relation to the presence of ornamental fountains and flowing water. These differences were not huge, perhaps being affected by the survey design and selection of parks to study. We also suggest that these key features of traditional parks could be further incorporated into contemporary ones in order to strengthen their cultural connectedness and to rediscover the sensory concentration system once used to such powerful effect but which would also help in the provision of benefits to modern users.

According to this study, the results we have presented reinforce the importance of considering recreation in the social life Iranian people and for promoting a healthier lifestyle. Most of the respondents we surveyed feel happy and satisfied when they are in parks with their friends and families undertaking a wide range of informal 'fun' activities. This revealed that in Iran, where family relationships are still strong, urban parks are important places for people to socialise with their families and friends. So parks directly or indirectly, support the quality of life.

Considering the spiritual factors that we examined, most people said that they go to parks to relax, reduce stress and to leave their cares behind. In Covid-19 times this aspect could be even more important for ensuring better mental well-being among urban citizens.

Author Contributions: Conceptualisation, F.B. and S.B.; methodology F.B.; data collection and analysis, F.B.; writing - original draft preparation, F.B. and S.B.; supervision, S.B. Both authors have read and agreed to the published version of the manuscript.

Funding: This research received no external funding.

Institutional Review Board Statement: The study was conducted according to the guidelines of the Declaration of Helsinki. Since the Estonian University of Life Sciences does not have its own ethical approval process for human studies, a University of Edinburgh level 1 ethics review was carried out which determined that as no sensitive or personal data were collected, people under 18 and 'vulnerable groups' were excluded from the sample, a formal ethical approval was unnecessary.

Informed Consent Statement: Informed consent was obtained from all subjects involved in the study.

Data Availability Statement: The data presented in this study are available on request from the corresponding author.

Acknowledgments: The authors thank Nasime Janatian Ghadikolaei for her assistance with statistical analysis and for reading and commenting on the text.

Conflicts of Interest: The authors declare no conflict of interest.

\section{Appendix A}

This is a translation of the questionnaire from the original language, Farsi. When it was handed out to respondents and they were given instructions on how to complete, they were asked to think about the park they were visiting at the time of the survey in order to enable comparisons between the parks to be conducted.

\section{Questionnaire on the Use of Parks and Green Space}

Please complete the following questionnaire relating to an investigation of priorities and design of urban parks according to the Iranian culture. Thank you very much for taking the time to complete this survey. No personal information will be collected that could identify you. By agreeing to complete the survey you provide informed consent for us to use the data we collect in our research.

1. Gender: Male $\square$ Female $\square$

2. Marital status: Single $\square$ Married $\square$ 
3. Age:

4. What is your employment status? Employee in government $\square$ Employee in private company $\square$ Unemployed $\square$ Retired $\square$ Homemaker $\square$

5. What is your educational level? Basic school $\square$ Under diploma $\square$ Diploma $\square$ Student $\square$ Bachelor $\square$ Master/Ph.D. $\square$

Please mark how much the following items are important for you in a park or green space?

\begin{tabular}{|c|c|c|c|c|c|}
\hline Item & VERY Low & Low & Moderate & High & Very High \\
\hline \multicolumn{6}{|l|}{ 1_There are appropriate places for sitting and relaxing } \\
\hline \multicolumn{6}{|l|}{ 2_There are opportunities for walking } \\
\hline \multicolumn{6}{|l|}{ 3_There are appropriate facilities for exercise } \\
\hline \multicolumn{6}{|l|}{ 4_There are opportunities to eat } \\
\hline \multicolumn{6}{|l|}{ 5_There are places to buy food } \\
\hline \multicolumn{6}{|l|}{ 6_There are opportunities to play informal games } \\
\hline \multicolumn{6}{|l|}{ 7_There are opportunities to cycle } \\
\hline \multicolumn{6}{|l|}{ 8_There are places for children to play and have fun } \\
\hline 9_The park is useable by older people & & & & & \\
\hline 10_There is availability of libraries and study facilities & & & & & \\
\hline
\end{tabular}

11_There is access to media

12_There are opportunities for group and social activities

13_There is the opportunity to paint or pursue art activities

14_It is possible to listen to and to observe nature

15_There are sufficient fountains

16_Theme park elements are provided

17_There are enough trees and flowers

18_The park is easy to access

19_There is an overall feeling of security and calmness

20_There are enough signs and information

21_The park is accessible by public transport

22_Souvenir or handicraft shops or stalls are available

23_Street furniture is light in colour

24_The park has a beautiful landscape design

25_There is enough lighting for when it is dark

26_There is a police presence at the park

27_The park is usable both day and night

28_There is enough shade

29_Being able to feel less stressful when in the park

30_There is flowing water

31_The park has music broadcasting

32_The park has enough playing fields

33_Spaces and equipment are physically safe 


\begin{tabular}{|c|c|c|c|c|c|}
\hline Item & VERY Low & Low & Moderate & High & Very High \\
\hline \multicolumn{6}{|l|}{ 34_ Being able to obtain inspiration } \\
\hline \multicolumn{6}{|l|}{ 35_ There are opportunities to spend time with family } \\
\hline \multicolumn{6}{|l|}{ 36_ There are opportunities to spend time with friends } \\
\hline \multicolumn{6}{|l|}{ 37_ There is access to the park by bicycle } \\
\hline \multicolumn{6}{|l|}{ 38_ There is access to the park by car } \\
\hline \multicolumn{6}{|l|}{39 _ There is access to the park on foot } \\
\hline \multicolumn{6}{|l|}{ 40_There are opportunities to leave cares behind } \\
\hline \multicolumn{6}{|l|}{ 41_ There are opportunities to be away from crowds } \\
\hline 42_ There are opportunities to feel revitalised & & & & & \\
\hline
\end{tabular}

\section{References}

1. United Nations. United Nations Department of Economics, 2005. World Population Policies; United Nations: New York, NY, USA, 2006.

2. Pauleit, S.; Ambrose-Oji, B.; Andersson, E.; Anton, B.; Buijs, A.; Haase, D.; Elands, B.; Hansen, R.; Kowarik, I.; Kronenberg, J.; et al. Advancing Urban Green Infrastructure in Europe: Outcomes and reflections from the GREEN SURGE project. Urban For. Urban Green. 2019, 40, 4-16. [CrossRef]

3. Sadeghi, R.; Zanjari, N. The Spatial Inequality of Development in the 22 Districts of Tehran Metropolis. Soc. Welf. Q. 2017, 17, 66.

4. Soltani, A.; Namdariyan, A. An Investigation of Forces Influence on Urban Space Formation. Hoviatshahr 2012, 4, 123-130.

5. Clark, P.; Jauhiainen, J. Introduction. In The European City and Green Space. London, Stockholm, Helsinki and St Petersburg, 1850-2000; Clark, P., Ed.; Routledge: Abingdon, UK, 2006.

6. Terkenli, T.S.; Bell, S.; Tošković, O.; Dubljević-Tomićević, J.; Panagopoulos, T.; Straupe, I.; Kristianova, K.; Straigyte, L.; O’Brien, L.; Živojinović, I. Tourist perceptions and uses of urban green infrastructure: An exploratory cross-cultural investigation. Urban For. Urban Green. 2020, 49, 1-12. [CrossRef]

7. Hansmann, R.; Hug, S.M.; Seeland, K. Restoration and stress relief through physical activities in forests and parks. Urban For. Urban Green. 2007, 6, 213-225. [CrossRef]

8. Salehi Fard, M. Rural Tourism, Fundamentals of Planning and Structural Projects; Marandiz Publications: Tehran, Iran, 2011.

9. Bahriny, F.; Bell, S. Patterns of Urban Park Use and Their Relationship to Factors of Quality: A Case Study of Tehran, Iran. Sustainability 2020, 12, 1560. [CrossRef]

10. Madanipour, A. City profile: Tehran. Cities 1999, 16, 57-65. [CrossRef]

11. Moradian, O.; Abdollah, Z. Evaluation of the Role of Urban Parks in urban Social Sustainability, Case Study (Azadi Park Shiraz city). J. Urban Res. Plan. 2019, 10, 113-128.

12. Gül, A.; Karaca, Ö. An approach for recreation suitability analysis to recreation planning in Gölcük Nature Park. Environ. Manag. 2006, 37, 606-625. [CrossRef]

13. Hamzenejad, M.; Gorji, F. Genealogy of Recent Parks of Tehran and Analyzing their Forming Background. Bagh-E Nazar 2018, $14,29-46$.

14. Hague, M.; Siegel, N. Municipal Parks in New York City: Olmsted, Riis, and the Transformation of the Urban Landscape, $1858-1897$. Transformations of Urban and Suburban Landscapes: Perspectives from Philosophy, Geography, and Architecture; Lexington Books: Lanham, MD, USA, 2002; pp. 153-191.

15. Milton, K. Environmentalism and Cultural Theory: Exploring the Role of Anthropology in Environmental Discourse; Routledge: Abingdon, UK, 2002.

16. Zhang, S.; Zhou, W. Recreational visits to urban parks and factors affecting park visits: Evidence from geotagged social media data. Landsc. Urban Plan. 2018, 180, 27-35. [CrossRef]

17. Behbahani, H. Development of Changing the Concept of Urban Parks from the 5th Century to the Current in the West; Organization of Parks \& Green Spaces of Tehran Municipality: Tehran, Iran, 2003.

18. Gehl, J.; Gemzøe, L. New City Spaces; Danish Architectural Press: Copenhagen, Denmark, 2001.

19. Daneshpour, S.A.; Charkchiano, M. Public spaces and factors affecting the collective life. J. Bagh Nazar 2007, 4, 19-28.

20. Bedimo-Rung, A.L. Environmental Determinants of Physical Activity in Parks: BRAT-Direct Observation Reference Manual, Version: May 24; Health Sciences Center: New Orleans, LA, USA, 2007.

21. Ghafouri, F.; Honari, H.; Ali, M. Iranian Physical Activity Priorities, a Nationwide Research; Physical Education Organization of Iran: Tehran, Iran, 2009.

22. Ghandehari, M.R.E.; Ghafouri, F.; Ganjooe, F.; Zarei, A. Urban parks users' profile: A case study in Iran. World Appl. Sci. J. 2012, 16, 892-897.

23. Pretty, J.N.; Griffin, M.; Peacock, J.; Hine, R.; Sellens, M.; South, N. A Countryside for Health and Wellbeing: The Physical and Mental Health Benefits of Green Exercise; Countryside Recreation Network: Sheffield, UK, 2005.

24. Barton, J.; Bragg, R.; Wood, C.; Pretty, J. (Eds.) Green Exercise: Linking Nature, Health and Well-Being; Routledge: Abingdon, UK, 2016. 
25. Andre, E.K.; Williams, N.; Schwartz, F.; Bullard, C. Benefits of Campus Outdoor Recreation Programs: A Review of the Literature. J. Outdoor Recreat. Educ. Leadersh. 2017, 9, 15-25. [CrossRef]

26. Puett, R.; Teas, J.; España-Romero, V.; Artero, E.G.; Lee, D.C.; Baruth, M.; Sui, X.; Montresor-López, J.; Blair, S.N. Physical activity: Does environment make a difference for tension, stress, emotional outlook, and perceptions of health status? J. Phys. Act. Health 2014, 11, 1503-1511. [CrossRef] [PubMed]

27. Levin, B.J.; Taylor, J. Depression, Anxiety, and Coping in Surfers. J. Clin. Sport Psychol. 2011, 5, 148-165. [CrossRef]

28. Tsaur, S.-H.; Lin, W.-R.; Cheng, T.-M. Toward a Structural Model of Challenge Experience in Adventure Recreation. J. Leis. Res. 2015, 47, 322-336. [CrossRef]

29. Crust, L.; Henderson, H.; Middleton, G. The acute effects of urban green and countryside walking on psychological health: A field-based study of green exercise. Int. J. Sport Psychol. 2013, 44, 160-177.

30. Manning, R.E.; Anderson, L.E.; Pettengill, P. Managing Outdoor Recreation: Case Studies in the National Parks; CABI: Wallingford, UK, 2017.

31. Schipperijn, J.; Ekholm, O.; Stigsdotter, U.K.; Toftager, M.; Bentsen, P.; Kamper-Jørgensen, F.; Randrup, T.B. Factors influencing the use of green space: Results from a Danish national representative survey. Landsc. Urban Plan. 2010, 95, 130-137. [CrossRef]

32. Wang, D.; Brown, G.; Liu, Y. The physical and non-physical factors that influence perceived access to urban parks. Landsc. Urban Plan. 2015, 133, 53-66. [CrossRef]

33. Jansson, M.; Fors, H.; Lindgren, T.; Wiström, B. Perceived personal safety in relation to urban woodland vegetation-A review. Urban For. Urban Green. 2013, 12, 127-133. [CrossRef]

34. Wendel, H.E.W.; Zarger, R.K.; Mihelcic, J.R. Accessibility and usability: Green space preferences, perceptions, and barriers in a rapidly urbanizing city in Latin America. Landsc. Urban Plan. 2012, 107, 272-282. [CrossRef]

35. Sugiyama, T.; Thompson, C.W. Associations between characteristics of neighbourhood open space and older people's walking. Urban For. Urban Green. 2008, 7, 41-51. [CrossRef]

36. Giles-Corti, B.; Broomhall, M.H.; Knuiman, M.; Collins, C.; Douglas, K.; Ng, K.; Lange, A.; Donovan, R.J. Increasing walking: How important is distance to, attractiveness, and size of public open space? Am. J. Prev. Med. 2005, 28, 169-176. [CrossRef]

37. Sharifi, G. Evolution and Adaption of the Iranian Garden to Modern Day Needs in Tehran. Master's Thesis, University of Science and Research, Tehran Branch, Tehran, Iran, 2016.

38. Bahrini, F.; Bell, S. Use of Public Parks in an Islamic Country in Transition: A Case Study of the Islamic Republic if Iran. In Proceedings of the European Council of Landscape Architecture Schools 2015 Conference "Landscapes in Flux", Estonian University of Life Sciences, Tartu, Estonia, 20-22 September 2015; pp. 140-145.

39. Suhardi, M. Seremban Urban Park, Malaysia: A Preference Study; Virginia Polytechnic Institute \& State University: Blackburg, VA, USA, 2002.

40. Pasban Hazrat, G. Design in Nature: Ferdosi Garden-Jamshidieh Garden-Environmental Design of Kolackchal Valleys; Ganje Honar Press: Tehran, Iran, 2009.

41. Rostami, R.; Lamit, H.; Khoshnava, S.M.; Rostami, R.; Rosley, M.S.F. Sustainable cities and the contribution of historical urban green spaces: A case study of historical Persian gardens. Sustainability 2015, 7, 13290-13316. [CrossRef]

42. Behbahani, H. Indicators and Characteristics of Gardening in the Qajar Period in Tehran; Tehran University Press: Tehran, Iran, 2014.

43. Daneshdoost, Y. Iranian Garden. Tehran Sci. Res. J. 1985, 1, 18-19.

44. Naima, G. Iranian Gardens; Payam Press: Tehran, Iran, 2006.

45. Shahcheraghi, A. An Introduction to the Reconstruction and Reconstruction of the Iranian Garden; Academic Jahad: Tehran, Iran, 2012.

46. Breuste, J.; Rahimi, A. Many public urban parks, but who profits from them? The example of Tabriz, Iran. Ecol. Process. 2015, 4, 6. [CrossRef]

47. Adler, M.; Ziglio, E. Gazing Into the Oracle: The Delphi Method and Its Application to Social Policy and Public Health; Jessica Kingsley Publishers: London, UK, 1996.

48. Roth, R.M.; Wood, W.C. A Delphi Approach to Acquiring Knowledge from Single and Multiple Experts. In Proceedings of the 1990 ACM SIGBDP Conference on Trends and Directions in Expert Systems, Orlando, FL, USA, 31 October-2 November 1990; pp. 301-324.

49. Hsu, C.C.; Sandford, B.A. The Delphi technique: Making sense of consensus. Pract. Assess. Res. Eval. 2007, 12, 1-8.

50. Brooks, K.W. Delphi technique: Expanding applications. North Cent. Assoc. Q. 1979, 53, 377-385.

51. Ary, D.V.; Biglan, A.; Glasgow, R.; Zoref, L.; Black, C.; Ochs, L.; Severson, H.; Kelly, R.; Weissman, W.; Lichtenstein, E.; et al. The efficacy of social-influence prevention programs versus "Standard care": Are new initiatives needed? J. Behav. Med. 1990, 13, 281-296. [CrossRef] [PubMed]

52. Agarwal, S.; Wills, J.; Cayton, L.; Lanckriet, G.; Kriegman, D.; Belongie, S. Generalized Non-Metric Multidimensional Scaling. In Proceedings of the Eleventh International Conference on Artificial Intelligence and Statistics, San Juan, Puerto Rico, 21-24 March 2007.

53. Becker, B.W. Perceived Similarities Among Recreational Activities. J. Leis. Res. 1976, 8, 112-122. [CrossRef]

54. Rezazadeh, R. The Role of Women in Good Governance; Metropolis Commission: Mashshad, Iran, 2005; Volume 5, pp. 21-23.

55. Ahmad, H.; Suhardi, M.; Manohar, M.; Shahhosseini, H. Users' preferences of usability and sustainability of old urban park in Tabriz, Iran. Aust. J. Basic Appl. Sci. 2011, 5, 1899-1905. 
56. Bahrini, F.; Bell, S.; Mokhtarzadeh, S. The relationship between the distribution and use patterns of parks and their spatial accessibility at the city level: A case study from Tehran, Iran. Urban For. Urban Green. 2017, 27, 332-342. [CrossRef]

57. Dastmalchian, A.; Javidan, M.; Alam, K. Effective Leadership and Culture in Iran: An Empirical Study. Appl. Psychol. 2001, 50, 532-558. [CrossRef]

58. Fakouhi, N. Urban Anthropology; Ney Press: Tehran, Iran, 2004.

59. Mozaffari, S.A.A.; Sabbaghian Rad, L.; Mohammadi Raoof, M.; Kazemi, H. Description of the Health Status in Sports Sets and Facilities of Tehran Municipality. Int. J. Basic Sci. Appl. Res. 2013, 2, 703-706. 